\title{
Spatial and seasonal variations, sources, air-soil exchange, and carcinogenic risk assessment for PAHs and PCBs in air and soil of Kutahya, Turkey, the province of thermal power plants
}

\author{
Yetkin Dumanoglu $^{\text {a }}$, Eftade O. Gaga ${ }^{\text {b }}$, Elif Gungormus ${ }^{\text {c }}$, Sait C. Sofuoglu ${ }^{\text {c,d }}$, Mustafa Odabasi a,* \\ a Department of Environmental Engineering, Faculty of Engineering, Dokuz Eylul University, Tinaztepe Campus, 35160 Buca, Izmir, Turkey \\ b Department of Environmental Engineering, Faculty of Engineering, Anadolu University, Iki Eylul Campus, 26555 Eskisehir, Turkey \\ c Department of Chemical Engineering, Izmir Institute of Technology, 35430 Gulbahce-Urla, Izmir, Turkey \\ d Department of Environmental Engineering, Izmir Institute of Technology, 35430 Gulbahce-Urla, Izmir, Turkey
}

\section{H I G H L I G H T S}

- Air and soil PAH and PCB levels were investigated around coal-fired power plants

- It was shown that power plants are major sources for PAHs and weak sources for PCBs

- PAHs mainly deposited to soil in winter while in summer they mostly volatilized

- For PCBs, volatilization was higher compared to deposition in both seasons

- Generally, estimated carcinogenic risks were below the acceptable risk level of $10^{-6}$

A R T I C L E I N F O

\section{Article history:}

Received 23 October 2016

Received in revised form 1 December 2016

Accepted 5 December 2016

Available online 8 December 2016

Editor: D. Barcelo

\section{Keywords:}

PAHs

PCBs

Air-soil exchange

Source apportionment

Carcinogenic risk
G R A P H I C A L A B S T R A C T

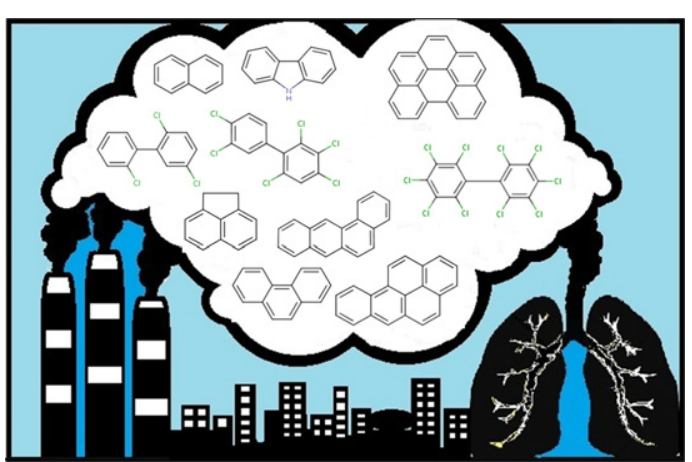

\footnotetext{
* Corresponding author.

E-mail address: mustafa.odabasi@deu.edu.tr (M. Odabasi).
} 
exceeding the acceptable risk level ranged from $<1 \%$ to $16 \%$, except, $32 \%$ of the inhalation risk levels due to PAH exposure in winter at urban/industrial sites were $>10^{-6}$.

(C) 2016 Elsevier B.V. All rights reserved.

\section{Introduction}

Polycyclic aromatic hydrocarbons (PAHs) are organic pollutants having two or more fused aromatic rings. PAHs are prevalent in environmental compartments like atmosphere, surface waters, sediment and soil (Motelay-Massei et al., 2003; Kaya et al., 2012), which are carcinogenic and mutagenic even at low levels (Ravindra et al., 2008; Wang et al., 2009). PAHs have natural (forest fires and volcanic activities) and anthropogenic sources (traffic, fossil fuel combustion, and industrial processes) (Aydin et al., 2014; Wang et al., 2015). Anthropogenic PAHs have either pyrogenic or petrogenic origins. Petrogenic sources are crude oil and petroleum products while pyrogenic PAHs emitted from incomplete combustion of fuels like coal and wood in industries and power plants (Okedeyi et al., 2013).

Polychlorinated biphenyls (PCBs) are anthropogenic persistent organic pollutants (POPs) that are widespread, toxic, and persistent in the environment, and could be transported to large distances (Biterna and Voutsa, 2005). PCBs were extensively used in various industrial applications like capacitors, transformers, and paints over the period of 1930-1975 (Dyke et al., 2003; Badawy et al., 2010; Gueguen et al., 2011). However, their production was discontinued and their use was banned in many countries several decades ago. PCBs are emitted into the environment from $\mathrm{PCB}$ containing wastes, open burning, waste incineration, evaporation from PCB containing products and contaminated surfaces, and accidental spills to soil (Vallack et al., 1998; UNEP, 1999; Breivik et al., 2002). PCBs could also form during the combustion of organic matter if chlorine is present (Weber et al., 2001). It was reported that PCB emissions from the combustion of different fuels (coal, wood, crude oil, gasoline/diesel) for industrial activities and power generation contribute to their atmospheric levels (Dyke et al., 2003; Biterna and Voutsa, 2005).

Coal is an important fuel for power generation in Turkey. Coal-fired thermal power plants are potentially the main air pollution source in Kutahya, Turkey, a province having two coal-fired power plants operating at their full capacities. PAHs already exist in coal but can also be formed during the combustion processes. Coal combustion also leads to the formation of PCBs (Lee et al., 2005). Therefore, it is important to explore the levels and profiles of PAHs and PCBs in the vicinity of coalfired power plants (Sahu et al., 2009).

The public perception about poor air quality in Kutahya and associated health effects is that the thermal power plants are the source of these problems. Since the air quality measurement studies are very limited even on conventional pollutants, and there has been no study investigating POP levels, an extensive sampling study covering the whole province was planned to investigate the PAH and PCB levels in the region. The specific objectives of this study were (1) to explore the spatial distributions and seasonal variations of PAH and PCB levels in air and soil, (2) to identify their possible sources, (3) to investigate their air-soil exchange, and (4) to determine the exposure to PAHs and PCBs and associated carcinogenic risks in Kutahya region, Turkey.

\section{Materials and methods}

\subsection{Study region}

The study area is Kutahya, a province in the Aegean region of Turkey, located in the inner western part of the country ( $38^{\circ} 70^{\prime}-39^{\circ} 80^{\prime} ; \mathrm{S}$ $29^{\circ} 00^{\prime}-30^{\circ} 30^{\prime}$ ). The province has a population of 571,554, of which 232,123 living in the City of Kutahya. The topography is characterized with mountains and hills and lowlands lying in the Northwest-Southeast direction. The main pollutant sources in the region are traffic, residential heating and industrial activities (especially power plants and mining). Coal is the primarily used fuel for residential heating and industrial activities due to its abundance as well as proximity of the lignite reserves around the city. Kutahya is characterized as a thermal power plant city because of the presence of two thermal power plants within the province (and within the sampling domain): Seyitomer Thermal Power Plant (600 MW), 20 km; Tuncbilek Thermal Power Plant (365 MW), $50 \mathrm{~km}$; and Orhaneli Thermal Power Plant (210 MW), within a neighboring province, $105 \mathrm{~km}$ away from the city center. Tuncbilek Thermal Power Plant is also located in the close vicinity of the second largest city of the province, Tavsanli. Other potential industrial sources located within the study area are sugar, ceramic, food, transportation, construction materials, boron mining and magnesite industries. All sampling sites, industries, and residential areas within the studied region are shown in Fig. 1.

\subsection{Sampling}

Ambient air $(n=82)$ and soil $(n=82)$ samples were collected during summer and winter periods at 41 sites (22 industrial/urban and 19 rural, Fig. 1). The sampling periods were: January 20-March 19, 2014 (winter) and June 02-August 05, 2014 (summer). Average air temperatures were 6.2 and $21.5{ }^{\circ} \mathrm{C}$ for winter and summer samplings, respectively.

Atmospheric samples were taken via polyurethane foam (PUF) disk passive air samplers (PAS). PUF disks (14 cm diameter, $1.35 \mathrm{~cm}$ thick, $365 \mathrm{~cm}^{2}$ surface area, $0.0213 \mathrm{~g} / \mathrm{cm}^{3}$ density, $4.40 \mathrm{~g}$ mass, and $207 \mathrm{~cm}^{3}$ volume) were placed in a stainless steel chamber made of two stainless-steel domes (top dome diameter $30 \mathrm{~cm}$, bottom dome diameter $20 \mathrm{~cm}$ ). Prior to sampling, depuration compounds (DCs) $\left({ }^{13} \mathrm{C}-\mathrm{PCB} 3\right.$, ${ }^{13}$ C-PCB $9,{ }^{13}$ C-PCB 15, PCB 30, РCB 107, and PCB 198), 17.5-20 ng per sample (dissolved in $10 \mathrm{~mL}$ hexane) were spiked into PUF disks to determine the compound-specific sampling rates. Then, hexane was evaporated using an $\mathrm{N}_{2}$ stream and PUFs were stored for $\sim 1$ week in their containers (pre-cleaned glass jars) in a freezer.

Surface soil samples were taken from the top $5 \mathrm{~cm}$. Equivalent quantities of 10 sub-samples taken from an $\sim 100 \mathrm{~m}^{2}$ area were integrated for each site. Then, the samples were passed through a $2.0 \mathrm{~mm}$ mesh sieve. About $10 \mathrm{~g}$ of soil samples was used for moisture content determination while $5 \mathrm{~g}$ of soil samples was used for PAH and PCB analysis. Soil total organic carbon (TOC) amounts were measured with a Total Organic Carbon Analyzer (Shimadzu, TOC-VCPN).

\subsection{Sample processing}

Before extraction, PAH and PCB surrogate standards dissolved in $0.5 \mathrm{~mL}$ hexane were added to all samples. Soxhlet extraction was applied for $12 \mathrm{~h}$ with 1:1 acetone:hexane (ACE:HEX) to ambient air PUFs. Soil samples ( $5 \mathrm{~g}$ ) were soaked in $20 \mathrm{~mL}$ of 1:1 ACE:HEX overnight. Then, they were extracted for $30 \mathrm{~min}$ in an ultrasonic bath. The extract volumes were concentrated to $2 \mathrm{~mL}$ and they were exchanged into HEX utilizing a rotary evaporator and a stream of $\mathrm{N}_{2}$. Samples were cleaned up and divided into two fractions using an alumina-silicic acid column packed with $3 \mathrm{~g}$ silicic acid (4.5\% water) and $2 \mathrm{~g}$ alumina (6\% water). PCBs were eluted with $35 \mathrm{~mL}$ petroleum ether (Fraction 1) while PAHs were eluted with $20 \mathrm{~mL}$ dichloromethane (Fraction 2). 


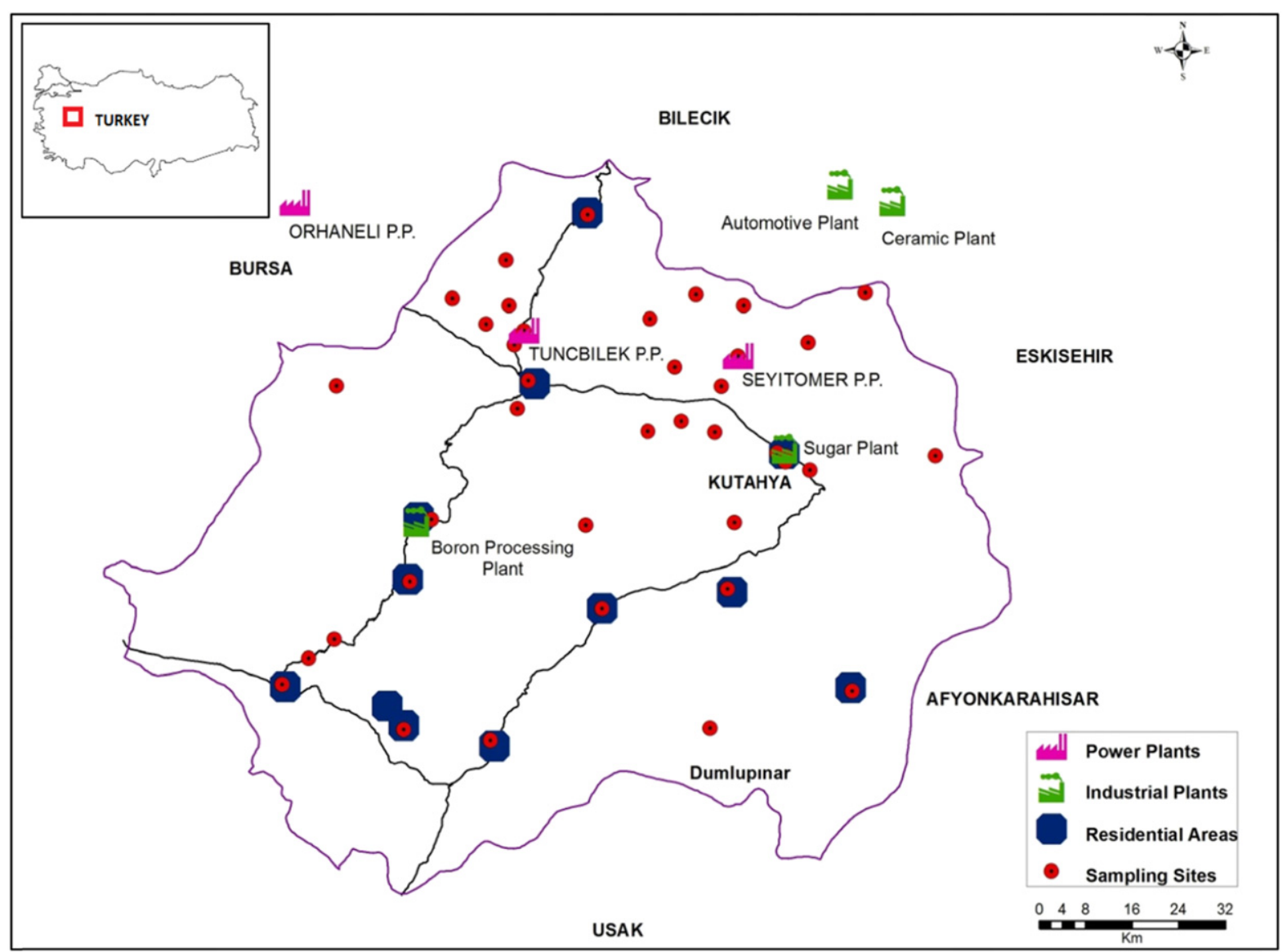

Fig. 1. Locations of the sampling sites $(n=41)$, industrial activities, and residential areas in the study region.

Extract solvents were switched into HEX and their volume was concentrated to $1 \mathrm{~mL}$ under a stream of $\mathrm{N}_{2}$.

\subsection{Instrumental analysis}

All samples were analyzed for 16 PAHs and 41 PCBs (see the Supplementary data for the analyzed compounds/congeners) using an Agilent $6890 \mathrm{~N}$ gas chromatograph (GC)-mass spectrometer (Agilent 5973 inert MSD) at electron impact ionization and selected ion monitoring mode (SIM). An HP5-MS capillary column ( $30 \mathrm{~m}, 0.25 \mathrm{~mm}, 0.25 \mu \mathrm{m}$ ) was utilized for the analysis and helium was the carrier gas. Fraction 1 was analyzed for PCBs. Then, for PAH analysis equal volumes of Fraction 1 and 2 were mixed and analyzed as lighter PAHs are eluted in part with Fraction 1. The identification of PAH compounds and PCB congeners was based on their retention times, target and qualifier ions, and their quantification was performed using internal standard calibration. Further details on sample processing and analysis have been reported previously (Cetin et al., 2007; Bozlaker et al., 2008a; Bozlaker et al., 2008b; Odabasi et al., 2009).

\subsection{Quality assurance/quality control}

Following surrogate standard recoveries (average \pm SD) were observed for air and soil samples: $71.6 \pm 11.4 \%$ (soil)-73.3 $\pm 12.4 \%$ (air) for acenaphthene- $\mathrm{d}_{10}, 74.3 \pm 10.6 \%$ (soil)-80.6 $\pm 14.9 \%$ (air) for phenanthrene- $\mathrm{d}_{10}, 78.9 \pm 13.9 \%$ (air)-82.4 $\pm 14.9 \%$ (soil) for chrysene- $\mathrm{d}_{12}$, $78.3 \pm 13.7 \%$ (air)-80.6 $\pm 17.9 \%$ (soil) for perylene- $\mathrm{d}_{12}, 65.7 \pm 10.5 \%$ (soil)-80.7 $\pm 13.4 \%$ (air) for PCB-14, $67.5 \pm 12.0 \%$ (soil) $82.9 \pm 13.0 \%$ (air) for PCB-65, $64.7 \pm 14.5 \%$ (soil)-73.9 $\pm 13.4 \%$ (air) for PCB-166. For $1 \mu \mathrm{L}$ injection, instrumental detection limits (IDL) were 0.15 and 0.10 pg for PAHs and PCBs, respectively. PAH and PCB levels in blank samples ( $n=3$ for each sample type) were also determined. Definition of the method detection limit (MDL) was: MDL = Mean blank value $+3 \mathrm{SD}$. For the compounds that could not be detected in blank samples, IDLs were substituted. The mean analyte quantities in blanks were generally $<5 \%$ of the sample quantities. Sample amounts above the MDL were quantified and they were corrected by subtracting the average blank levels from those in samples.

Sampling rates $\left(R, \mathrm{~m}^{3}\right.$ day $\left.^{-1}\right)$ for air samples determined using the loss of spiked DC amounts varied from 0.73 to $5.15 \mathrm{~m}^{3}$ day $^{-1}(2.20 \pm$ $0.80 \mathrm{~m}^{3} \mathrm{day}^{-1}$, average $\pm \mathrm{SD}$ ) for winter, 2.54 to $5.72 \mathrm{~m}^{3}$ day $^{-1}$ $\left(3.56 \pm 0.72 \mathrm{~m}^{3} \mathrm{day}^{-1}\right.$, average $\left.\pm \mathrm{SD}\right)$ for summer. The effective air sampling volumes $\left(V_{\mathrm{air}}, \mathrm{m}^{3}\right)$ for individual PAHs and PCBs for the sampling periods were estimated using the method developed by Shoeib and Harner (2002). Sampling rate and effective sampling volume calculations were detailed by Kaya et al. (2012). For the calculation of $V_{\text {air }}$, it was assumed that the sampling rates for both gas-phase and particlephase compounds were similar (Harner et al., 2014; Harner et al., 2013).

\subsection{Estimation of gas-phase concentrations}

PUF disk passive air samplers mainly target gas-phase compounds. However, recent studies have implied that they also collect particles, the sampling rates are typically in the range $4 \pm 2 \mathrm{~m}^{3}$ day ${ }^{-1}$ both for gas-and particle-phase compounds, and consequently these samplers measure total (gas + particle phase) concentrations (Markovic et al., 2015; Harner et al., 2014; Harner et al., 2013). Since gas-phase concentrations are needed to assess air-soil gas exchange of pollutants, atmospheric total (gas + particle phase) PAH and PCB levels measured with passive samplers were used to estimate the gas-phase concentrations in the present study. 
Distribution of semivolatile organic compounds between the gas and particle phases is explained using the gas-particle partition coefficient, $K_{\mathrm{p}}\left(\mathrm{m}^{3} \mu \mathrm{g}^{-1}\right)$ (Harner and Bidleman, 1998):

$K_{p}=\left(C_{p} / C_{T S P}\right) / C_{g}$

where $C_{p}$ and $C_{g}$ are the concentrations in the particle and gas-phases, respectively ( $\mathrm{ng} \mathrm{m}^{-3}$ ), and $C_{T S P}$ is the atmospheric total suspended particulate concentration $\left(\mu \mathrm{g} \mathrm{m}^{-3}\right)$.

The octanol-air partition coefficient $\left(K_{\mathrm{OA}}\right)$ and organic matter fraction of particles $\left(f_{O M}\right)$ were used to estimate $K_{\mathrm{p}}$ assuming that the major distribution route is absorption (Harner and Bidleman, 1998):

$\log K_{p}=\log K_{O A}+\log f_{O M}-11.91$

Gas-phase concentrations were estimated as:

$C_{g}=C_{t}\left\{1-\left[\left(K_{p} C_{T S P}\right) /\left(1+K_{p} C_{T S P}\right)\right]\right\}$

where $C_{t}$ is the total (gas + particle phase) concentration measured with the PUF disk passive air sampler.

Temperature $(T)$ dependent $K_{\mathrm{OA}}$ values of the PAHs and PCBs (log $\left.K_{\mathrm{OA}}=A+B / T\right)$ were calculated using the constants $(A$ and $B$ ) reported by Odabasi et al. (2006a), Odabasi et al. (2006b), Harner and Bidleman (1996), Chen et al. (2002), Zhang et al. (1999). Recently measured $\mathrm{PM}_{10}$ concentrations at two sites (urban and rural) in Kutahya and their organic carbon (OC) content was used for the calculation of $K_{\mathrm{p}}$ and gas-phase fractions at different sites based on their classification (i.e., urban/industrial, rural). $\mathrm{PM}_{10}$ concentrations were $34.8 \pm$ $30.3 \mu \mathrm{g} \mathrm{m} \mathrm{m}^{-3}$ and $52.7 \pm 36.6 \mu \mathrm{g} \mathrm{m}^{-3}$ while OM fractions were $0.39 \pm 0.20 \%$ and $0.53 \pm 0.19 \%$ at the urban and rural sites, respectively (Gaga, 2016). OM fraction was assumed to be 1.5 times the OC fraction.

\subsection{Calculation of fugacity fractions}

Air-soil gas exchange of PAHs and PCBs is an important transport mechanism since some compounds partition substantially to gasphase. Fugacity is a quantity of chemical potential of a pollutant in a specific compartment that drives its transfer between media (Meijer et al., 2001). The equilibrium partitioning of a pollutant between air and soil is described by the soil-air partition coefficient, $K_{\mathrm{SA}}$ (dimensionless) as follows (Meijer et al., 2003):

$K_{S A}=\frac{C_{s} \rho_{s}}{C_{g}}$

where $C_{\mathrm{S}}$ is the soil concentration ( $\mathrm{ng} \mathrm{kg}^{-1}$, dry weight), $\rho_{\mathrm{s}}$ is the soil solid density $\left(\mathrm{kg} \mathrm{m}^{-3}\right)$, and $C_{\mathrm{g}}$ is the atmospheric gas-phase concentration $\left(\mathrm{ng} \mathrm{m}^{-3}\right)$.

$K_{\mathrm{SA}}$ depends on temperature, physicochemical properties of pollutant, and soil properties (i.e., humidity, organic carbon content) (Meijer et al., 2003). Absorption to the organic carbon fraction is the primary mechanism for partitioning of POPs to soil (Harner et al., 2000). Hippelein and McLachlan (1998) derived a linear relationship that correlates $K_{\mathrm{SA}}$ to octanol-air partition coefficient $\left(K_{\mathrm{OA}}\right)$ and the organic carbon fraction of the soil:

$K_{S A}=0.411 \rho_{S} \varnothing_{O C} K_{O A}$

where $\rho_{\mathrm{s}}$ is the soil solid density $\left(\mathrm{kg} \mathrm{L}^{-1}\right)$ and $\phi_{\mathrm{OC}}$ is the fraction of organic carbon on a dry soil basis. In the calculation of $K_{\mathrm{SA}}$, it is assumed that the soil fugacity capacity results fully from the organic carbon fraction (Bidleman and Leone, 2004; Meijer et al., 2001).
Soil fugacity fractions $\left[f_{\mathrm{S}} /\left(f_{\mathrm{S}}+f_{\mathrm{A}}\right)\right]$ were calculated to assess the direction of exchange of individual PAHs and PCBs between the soil and air interface as:

$f_{S} /\left(f_{S}+f_{A}\right)=\left(C_{S} \rho_{S} / K_{S A}\right) /\left[\left(C_{S} \rho_{S} / K_{S A}\right)+C_{g}\right]$

Fugacity fractions for individual PAHs and PCBs were calculated using Eqs. (3)-(6) to determine their direction of air-soil exchange. Temperature $(T)$ dependent $K_{\mathrm{OA}}$ values of the PAHs and PCBs (log $\left.K_{\mathrm{OA}}=A+B / T\right)$ were determined using the parameters ( $A$ and $B$ ) given by Odabasi et al. (2006a), Odabasi et al. (2006b), Harner and Bidleman (1996), Chen et al. (2002), Zhang et al. (1999). The average organic carbon content of soil samples was measured as $3.50 \pm 1.81 \%$ (average $\pm \mathrm{SD}$, in dry mass). The measured average density of soil solids $\left(2.0 \pm 0.1 \mathrm{~g} \mathrm{~cm}^{-3}, n=6\right)$ was used for fugacity fraction estimations.

\subsection{Factor analysis}

Factor analysis was used to explore the sources of PAHs and PCBs (SPSS version 20.0 for Windows, SPSS Inc.). The input variables were the atmospheric PAH and PCB levels determined by the passive sampling. All the PAH compounds were detected almost in every sample and they were included in the analysis while 21 PCBs that were detected in majority of the samples ( $>70 \%$ ) were included. Below detection limit values were replaced with $1 / 2$ of the MDL. The extraction method was principal component analysis while Varimax with Kaiser Normalization was the rotation method. Only major principal components (PCs) were retained with eigenvalues $>1.0$ and significant clusters defined by factor loading coefficients $>0.5$.

\subsection{Exposure and risk assessment}

Exposure for the routes of inhalation and accidental soil ingestion was assessed, and carcinogenic health risk assessment was conducted. As an estimation of inhalation exposure, the following equation recommended by USEPA (2011) was used:

$\sum_{\mathrm{j}}^{\mathrm{J}} \mathrm{iCDI}=\frac{\mathrm{C}_{\mathrm{j}} \times \mathrm{IR} \times \mathrm{ED} \times \mathrm{EF}}{\mathrm{BW} \times \mathrm{AT}}$

where $C_{j}$ is the BaP equivalents ( $\mathrm{BaP}_{\mathrm{eq}}$ ) for each $\mathrm{PAH}$ compound concentration or concentration of each non-dioxin like PCB congener or 2,3,7,8tetrachlorodibenzo-p-dioxin toxic equivalents for each dioxin-like PCB congener $\left(\mathrm{ng} \mathrm{m}^{-3}\right)$, IR is inhalation rate $\left(\mathrm{m}^{3} \mathrm{day}^{-1}\right), E D$ is exposure duration (yr), $E F$ is exposure frequency (days $\mathrm{yr}^{-1}$ ), $B W$ is body weight $(\mathrm{kg}), A T$ is averaging time $\left(\mathrm{ED} \times 365\right.$ days $\left.\mathrm{yr}^{-1}\right)$, and $i C D I$ is inhalation chronic daily intake (ng kg ${ }^{-1} \mathrm{day}^{-1}$ ). Concentrations of targeted PAHs and dioxin-like PCBs (PCB 105, 118, 156, and 169) were converted to $\mathrm{BaP}_{\mathrm{eq}}$ and 2,3,7,8-tetrachlorodibenzo-p-dioxin toxic equivalents, respectively, by using toxic equivalent factors (TEFs) proposed by Nisbet and LaGoy (1992), Larsen and Larsen (1998), USEPA (2002a), and USEPA (2010), shown in Table S1. Although some data for Turkish people living in urban settings are available in the literature, no time budgets have been determined for people living in rural areas. Therefore, time spent daily indoors at home, other indoor locations, outdoors, and in vehicles for the urban and rural adult population was taken from literature (Matz et al., 2015). Average hours per day spent in each microenvironment by different activity levels (resting, light, moderate, and heavy) for all age groups were taken from USEPA (2011). These two data sets were combined to obtain daily time spent by resting, light, moderate, and heavy activities in indoor, outdoor, and in vehicle environments. The intake rates as a function of activity, reported in EPA Exposure Factor Handbook (USEPA, 2011), were multiplied with the calculated daily time spent by different activity levels in each microenvironment. Finally, the inhalation rate for adults living in rural and 
urban/industrial sites were estimated as 16.63 and $15.71 \mathrm{~m}^{3}$ day ${ }^{-1}$, respectively. Distribution of $B W$ (lognormal distribution; mean = $65.56 \mathrm{~kg}$, standard deviation $=13.02 \mathrm{~kg}$ ) was taken from Kavcar et al. (2006). ED was assumed as 70 years for lifetime exposure and $E F$ was 180 days $\mathrm{yr}^{-1}$ for both winter and summer.

$C D I$ was also calculated as an estimate of accidental soil ingestion exposure for $\Sigma_{16}$ PAHs and $\Sigma_{41}$ PCBs (ATSDR, 2005):

$\sum_{\mathrm{k}}^{\mathrm{K}} \mathrm{siCDI}=\frac{\mathrm{C}_{\mathrm{k}} \times \mathrm{IR} \times \mathrm{AF} \times \mathrm{ED} \times \mathrm{EF} \times \mathrm{CF}}{\mathrm{BW} \times \mathrm{AT}}$

where $C_{k}$ is the BaP equivalents ( $\mathrm{BaP}_{\mathrm{eq}}$ ) for each $\mathrm{PAH}$ compound in soil or concentration of each nondioxin like PCB congener in soil or 2,3,7,8tetrachlorodibenzo-p-dioxin toxic equivalents for each dioxin-like PCB congener in soil $\left(\mu \mathrm{kg}^{-1}\right)$, IR is soil ingestion rate $\left(\mathrm{mg} \mathrm{day}^{-1}\right), A F$ is absorption factor for the gastrointestinal tract (dimensionless), $E D$ is exposure duration (yr), EF is exposure frequency (days $\mathrm{yr}^{-1}$ ), CF is conversion factor $\left(10^{-6} \mathrm{~kg} \mathrm{mg}^{-1}\right), B W$ is body weight $(\mathrm{kg}), A T$ is averaging time $\left(E D \times 365\right.$ days $\left.\mathrm{yr}^{-1}\right)$, siCDI is accidental soil ingestion chronic daily intake ( $\mu \mathrm{g} \mathrm{kg}^{-1} \mathrm{day}^{-1}$ ). Similar to the calculation of inhalation exposure, the concentrations of the targeted PAH compounds and dioxinlike PCBs were converted to $\mathrm{BaP}_{\mathrm{eq}}$ and dioxin toxic equivalent by using their individual TEF values. Distribution of soil ingestion rate for adults (uniform distribution; minimum $=0 \mathrm{mg} /$ day, maximum $=$ $130 \mathrm{mg} \mathrm{day}^{-1}$ ) was taken from USEPA (2002b). AF was assumed as 1 as recommended by Health Canada (2004). EF, ED, BW, and $A T$ are the same as used in the calculation of inhalation exposure.

Cancer risks associated with inhalation and accidental ingestion exposure to $\Sigma_{16}$ PAHs and $\Sigma_{41}$ PCBs were calculated by using Eq. (9) (USEPA, 2005; USEPA, 1996). The total carcinogenic risk for PCBs was calculated as the summation of risk levels due to dioxin-like and non-dioxin-like PCBs.

$\mathrm{R}=\mathrm{CDI} \times \mathrm{SF}$

where $\mathrm{R}$ is excess cancer risk, $S F$ is slope factor of the contaminants. All SF values were taken from CalEPA (2015) and USEPA (2007), tabulated in Table S2.

Monte Carlo simulation was carried out for the population exposure/ risk assessment by using Crystal Ball software (v 4.0e). Statistical sampling techniques are used in this simulation to approximate output of a model or a mathematical equation probabilistically. A probability distribution was fitted to each input variable of the exposure-risk model by testing eight continuous distributions, and ranking them by goodnessof-fit tests (Kolmogorov-Smirnov (KS) and Anderson-Darling (AD)). The simulation was run 10,000 times, creating a sample of estimated exposure/risks, for which a probability distribution is fitted as explained above. The simulation software was also used to estimate uncertainty associated with the Monte-Carlo process by using bootstrap analysis with 200 simulations of 1000 trials each.

\section{Results and discussion}

3.1. Spatial distribution and seasonal variations of atmospheric PAHs and PCBs

Atmospheric PAH and PCB levels are presented in Tables S3 and S4. $\Sigma_{16}$ PAH levels observed in the present study were greatly variable (9.71-1164.5 $\mathrm{ng} \mathrm{m}^{-3}$ ) in winter and (3.04-131.7 $\mathrm{ng} \mathrm{m}^{-3}$ ) in summer. Fig. 2 shows the spatial variation of atmospheric PAH levels $\left(\mathrm{ng} \mathrm{m}^{-3}\right)$ for summer and winter periods. Atmospheric total PAH concentrations were comparable to those measured in other industrial areas in Turkey (Odabasi et al., 2015; Odabasi et al., 2016). PAH concentrations were significantly higher in winter $(p<0.01)$ especially at residential sites, suggesting that concentrations observed in winter were mainly contributed by residential heating emissions (Odabasi et al., 2006a; Vardar et al., 2008; Aydin et al., 2014). For all periods, site-average $\Sigma_{16} \mathrm{PAH}$ concentrations were approximately 10 times higher near power plants and residential sites compared to non-residential sites. Similar observations have been reported by recent studies (Okedeyi et al., 2013; Wang et al., 2015).

Low to medium molecular weight compounds (i.e., phenanthrene, fluorene, fluoranthene, and pyrene) dominated the $\Sigma_{16} \mathrm{PAH}$ concentrations measured in ambient air (Table S3). Those low molecular PAH compounds have been found as dominant PAHs in Turkey and all around the world (Bozlaker et al., 2008a; Sahu et al., 2009; Kaya et al., 2012; Demircioglu et al., 2011; Okedeyi et al., 2013; Wang et al., 2015).

$\Sigma_{41}$ PCB concentrations were also highly variable and ranged between 19.6 and $675.1 \mathrm{pg} \mathrm{m}^{-3}$ in winter and $31.6-230.2 \mathrm{pg} \mathrm{m}^{-3}$ in summer. On the average, atmospheric PCB concentrations were 1.5 times higher in winter compared to those measured in summer (Fig. 3). This suggests that increased coal combustion due to residential heating may have contributed to wintertime PCB levels (Biterna and Voutsa, 2005). However, it should also be noted that decreasing mixing height during winter may cause increasing pollutant concentrations. The highest concentrations were observed at sites which are impacted by both residential areas and power plants whereas the lowest ones were measured in rural sites. The concentrations of PCBs in this study were within the range reported for urban and power plant areas (Biterna and Voutsa, 2005; Bozlaker et al., 2008b; Odabasi et al., 2008) while they were lower than those observed in industrial areas (Odabasi et al., 2015; Odabasi et al., 2016). Low molecular weight congeners (PCB$17,18,28,31,33,44,49$, and 52) dominated the $\Sigma_{41}$ PCB concentrations in both seasons (Table S4).

\subsection{Spatial distribution and seasonal variations of soil $P A H$ and $P C B$ concentrations}

PAH and PCB levels determined in soil samples are presented in Tables S5 and S6. $\Sigma_{16}$ PAH concentrations in soil ranged between 56 and $3114.2 \mu \mathrm{g} \mathrm{kg}^{-1}$ in winter, 36.47 to $1435.4 \mu \mathrm{g} \mathrm{kg}^{-1}$ (dry weight) in summer. Similar to wintertime and summertime atmospheric levels, the highest soil PAH levels were measured near the power plants and residential areas (Fig. 4). On the average, soil PAH concentrations were 2.3 times higher in winter compared to those measured in summer. Lower soil PAH concentrations measured in summer could be attributed to loss of PAHs from soil via volatilization under substantially lower atmospheric concentrations and higher temperatures during summer (see Section 3.4). Other possible loss mechanisms from soil are biodegradation, photolysis, and chemical degradation that are more effective during summer (Ayris and Harrad, 1999; Ukiwe et al., 2013). However, in the present study it is not possible to assess the extent of PAH loss from soil due to these mechanisms. Total PAH concentrations in soil samples taken from the surroundings of power plants were higher than those measured in a recent study conducted in a South Africa power plant area (Okedeyi et al., 2013) and comparable to those measured in other industrial areas in Turkey (Odabasi et al., 2010; Odabasi et al., 2015; Odabasi et al., 2016). Medium to high molecular weight compounds (phenanthrene, fluoranthene, pyrene, chrysene, benzo $[b]$ fluoranthene, benzo[ $k]$ fluoranthene) were prevalent for soil $\Sigma_{16}$ PAHs.

$\Sigma_{41}$ PCBs in soil varied from 0.50 to $8.30 \mu \mathrm{kg}^{-1}$ in winter, 1.20 to $9.90 \mu \mathrm{g} \mathrm{kg}^{-1}$ (dry weight) in summer. The seasonal variation of soil $\Sigma_{41}$ PCB concentrations in the study area was not substantial with an overall winter/summer ratio of 1.16. Soil PCB levels were similar to previously measured values in this area (Gedik and Imamoglu, 2011) while they were lower than the mean PCB levels observed in other industrial areas of Turkey (Odabasi et al., 2010; Kaya et al., 2012). Generally, higher values were measured around power plants and residential areas (Fig. 5). Unlike the air concentrations, there were not any dominant PCB congeners measured in soil samples during winter and summer periods. 


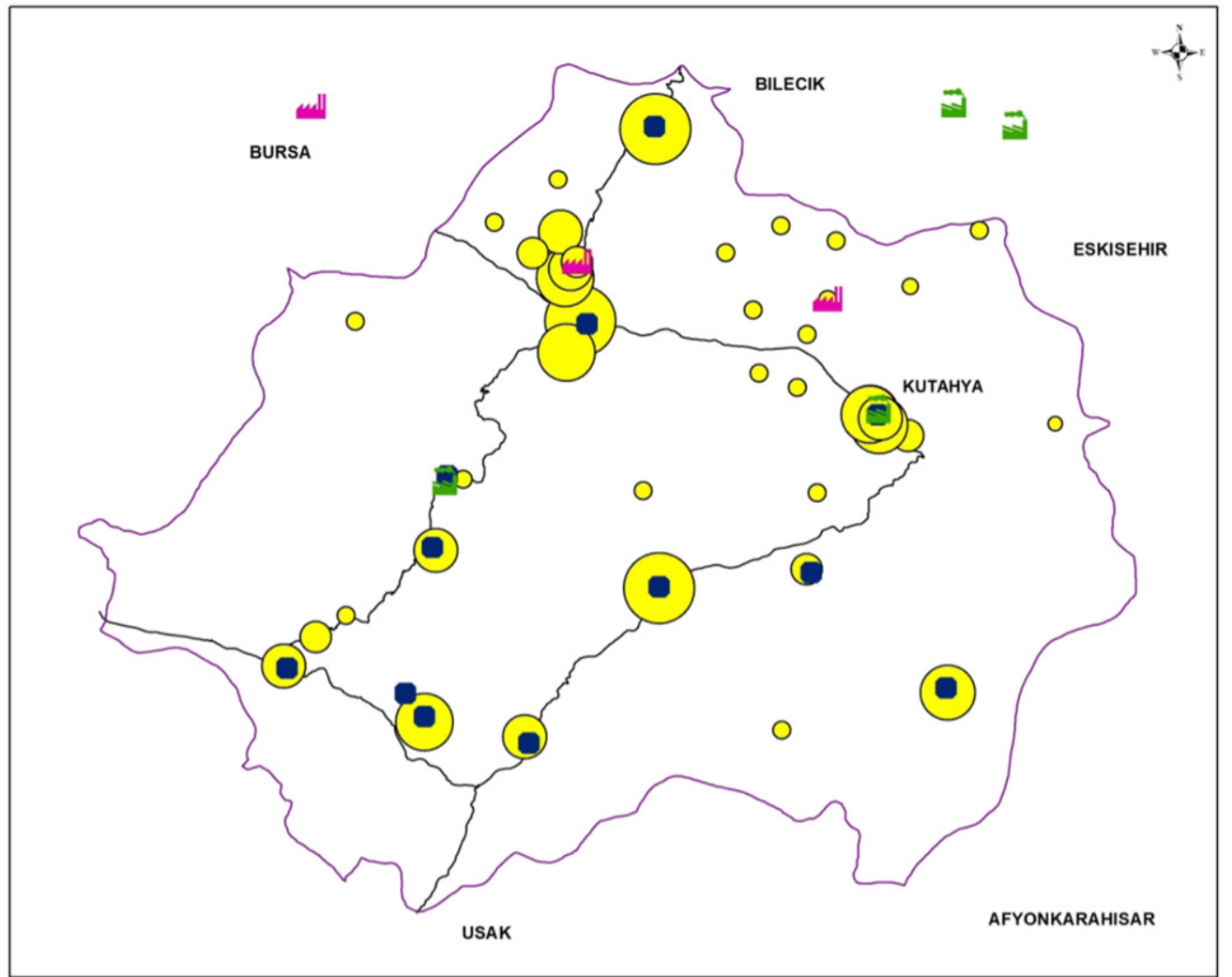

Air (winter)

\16PAH $\left(\mathrm{ng} \mathrm{m}^{-3}\right)$

O $15-50$

50-100

○ $100-300$

$\bigcirc 300-700$

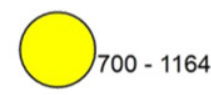

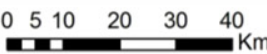

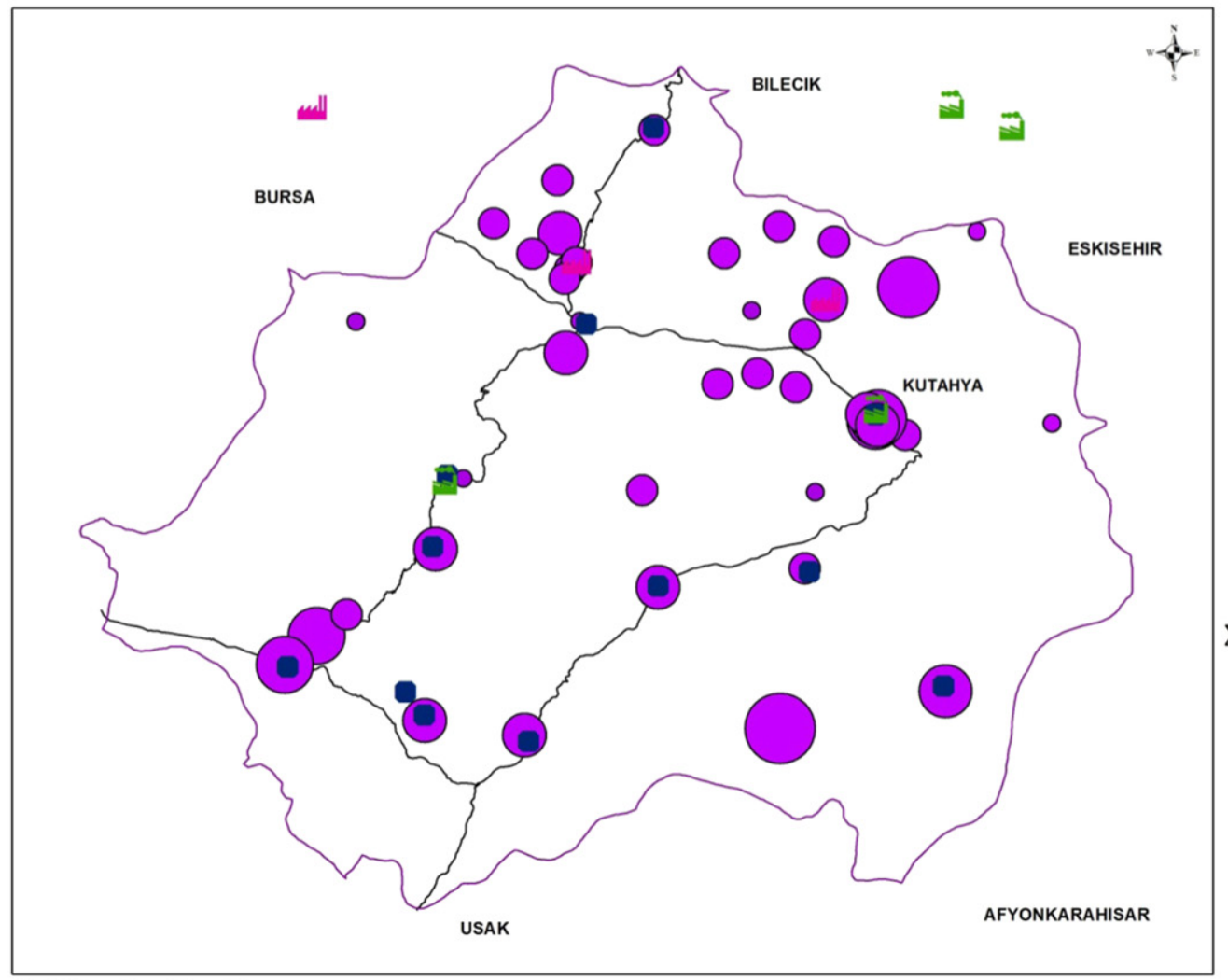

Air (summer) I16PAH $\left(\mathrm{ng} \mathrm{m}^{-3}\right)$

- 3-10

$10-20$

$20-29$

$30-45$

$\begin{array}{lllll}0 & 510 & 20 & 30 & 40\end{array}$

Fig. 2. Spatial distribution of atmospheric $\Sigma_{16} \mathrm{PAH}$ concentrations $\left(\mathrm{ng} \mathrm{m}^{-3}\right)$ in Kutahya region. 


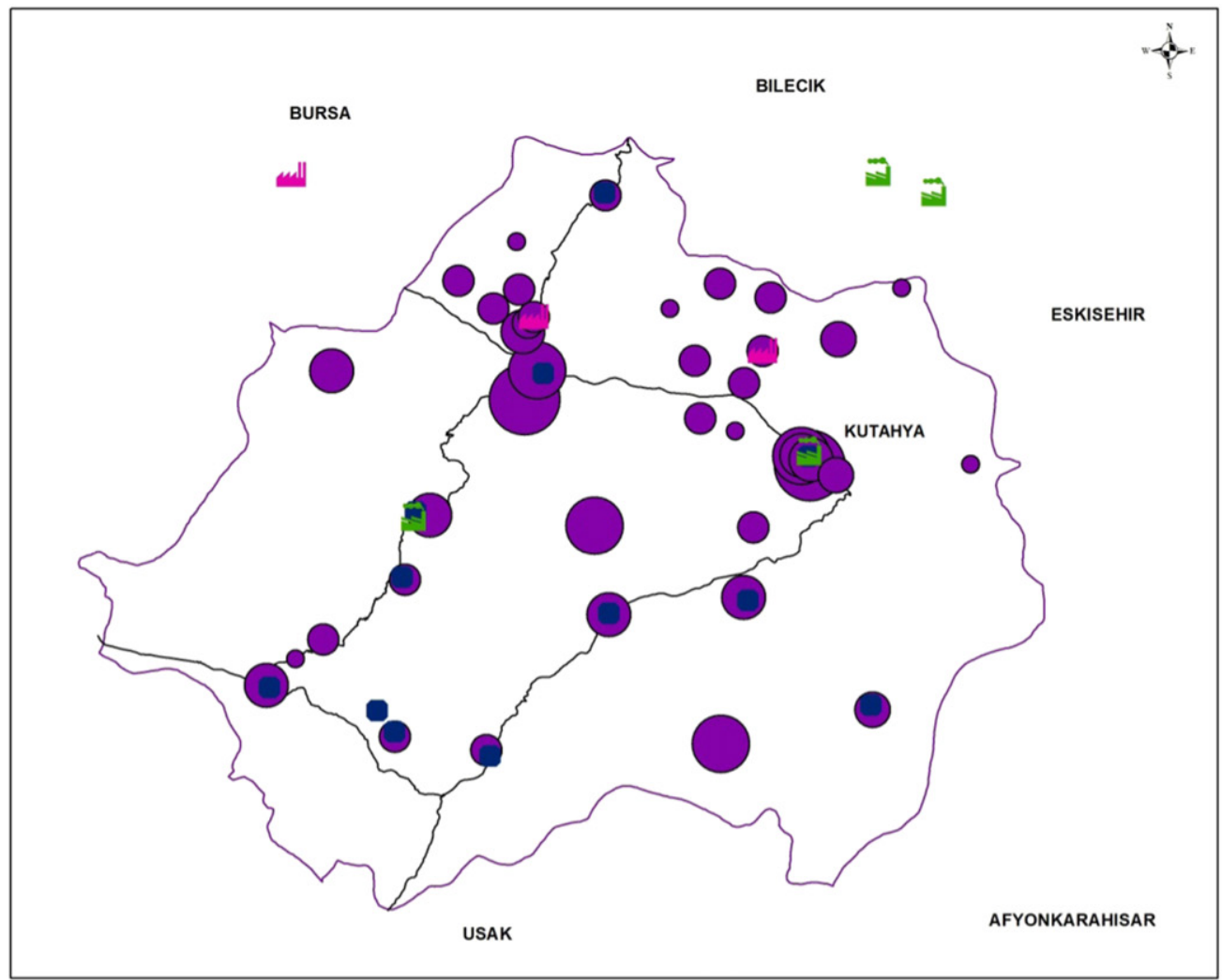

Air (winter) ¿41PCB $\left(\mathrm{pg} \mathrm{m}^{-3}\right)$

- $28-100$

100-150

$150-250$

$250-450$

\begin{tabular}{lllll}
0 & 510 & 20 & 30 & 40 \\
\hline $\mathbf{m}$ & $\mathbf{P}$ & $\mathbf{1 0}$ & $\mathrm{Km}$
\end{tabular}

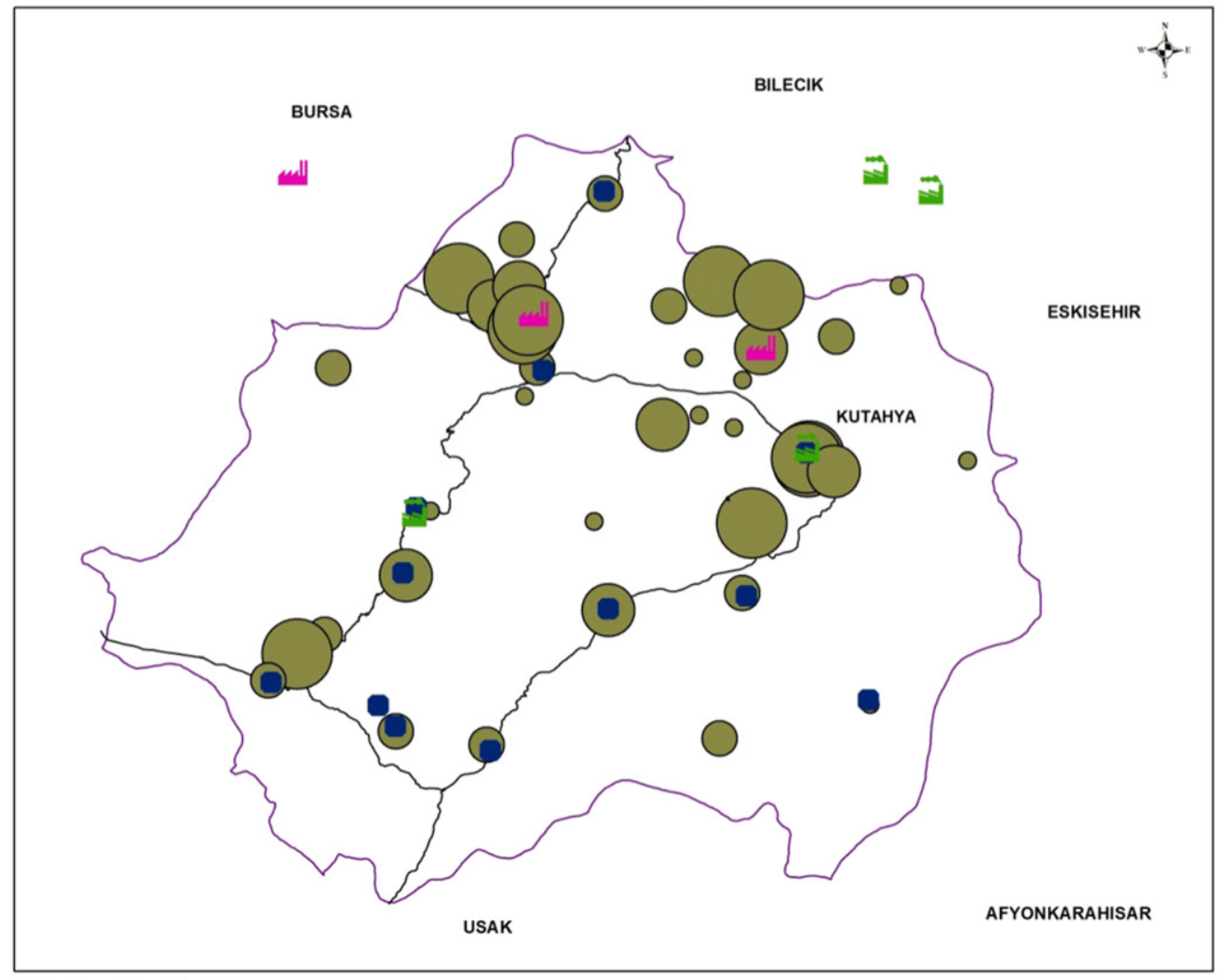

4.

Air (summer)

¿41PCB $\left(\mathrm{pg} \mathrm{m}^{-3}\right)$

○ $32-100$

$100-125$

$125-150$

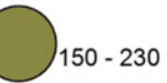

$\begin{array}{lllll}0 & 510 & 20 & 30 & 40\end{array}$

Km

Fig. 3. Spatial distribution of atmospheric $\Sigma_{41} \mathrm{PCB}$ concentrations $\left(\mathrm{pg} \mathrm{m}^{-3}\right)$ in Kutahya region. 


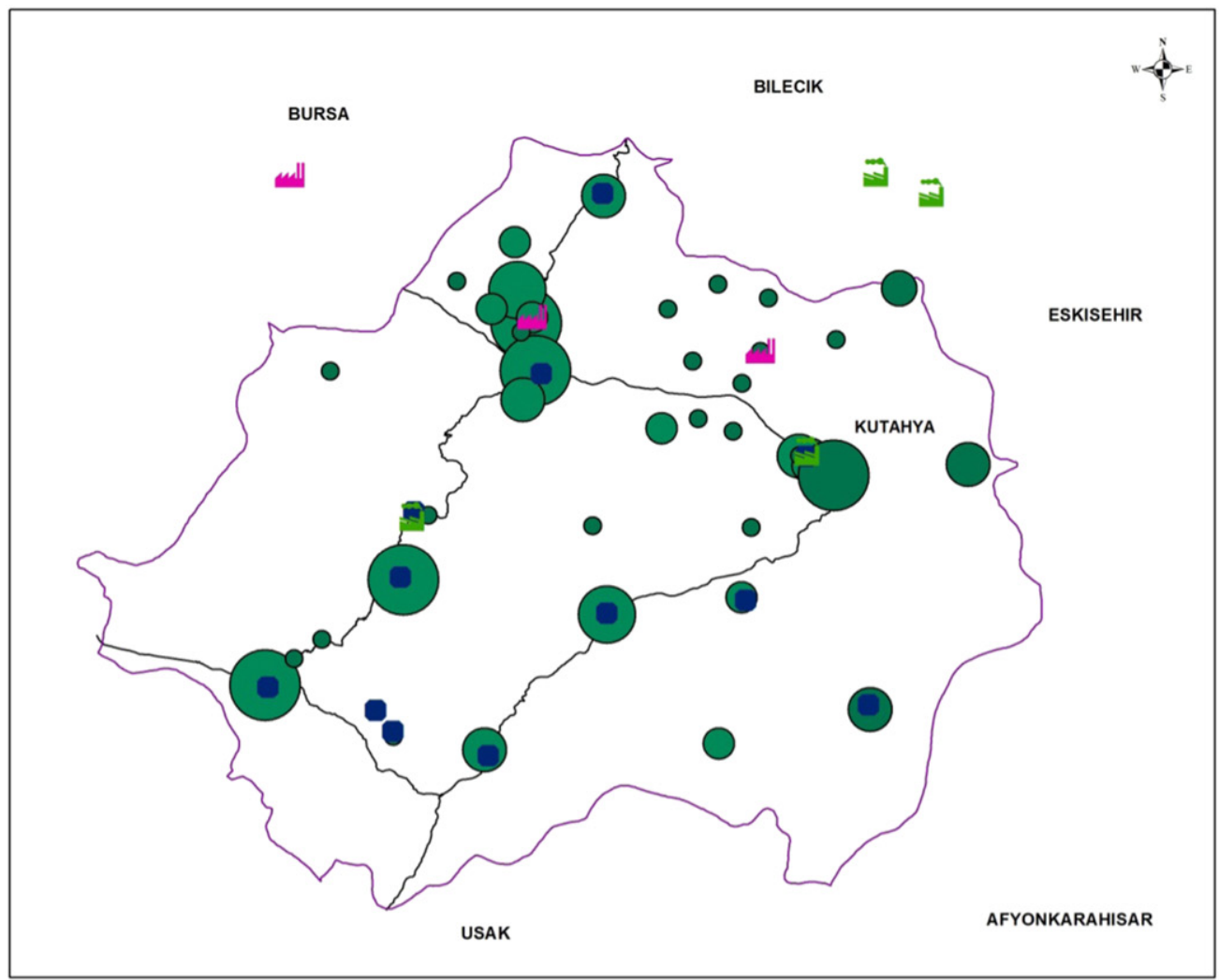

Soil (winter) $\sum 16 \mathrm{PAH}\left(\mu \mathrm{g} \mathrm{kg}^{-1}\right)$

○ $57-150$

○ $150-350$

○ $350-850$

$850-1800$

$\begin{array}{lllll}0 & 510 & 20 & 30 & 40\end{array}$

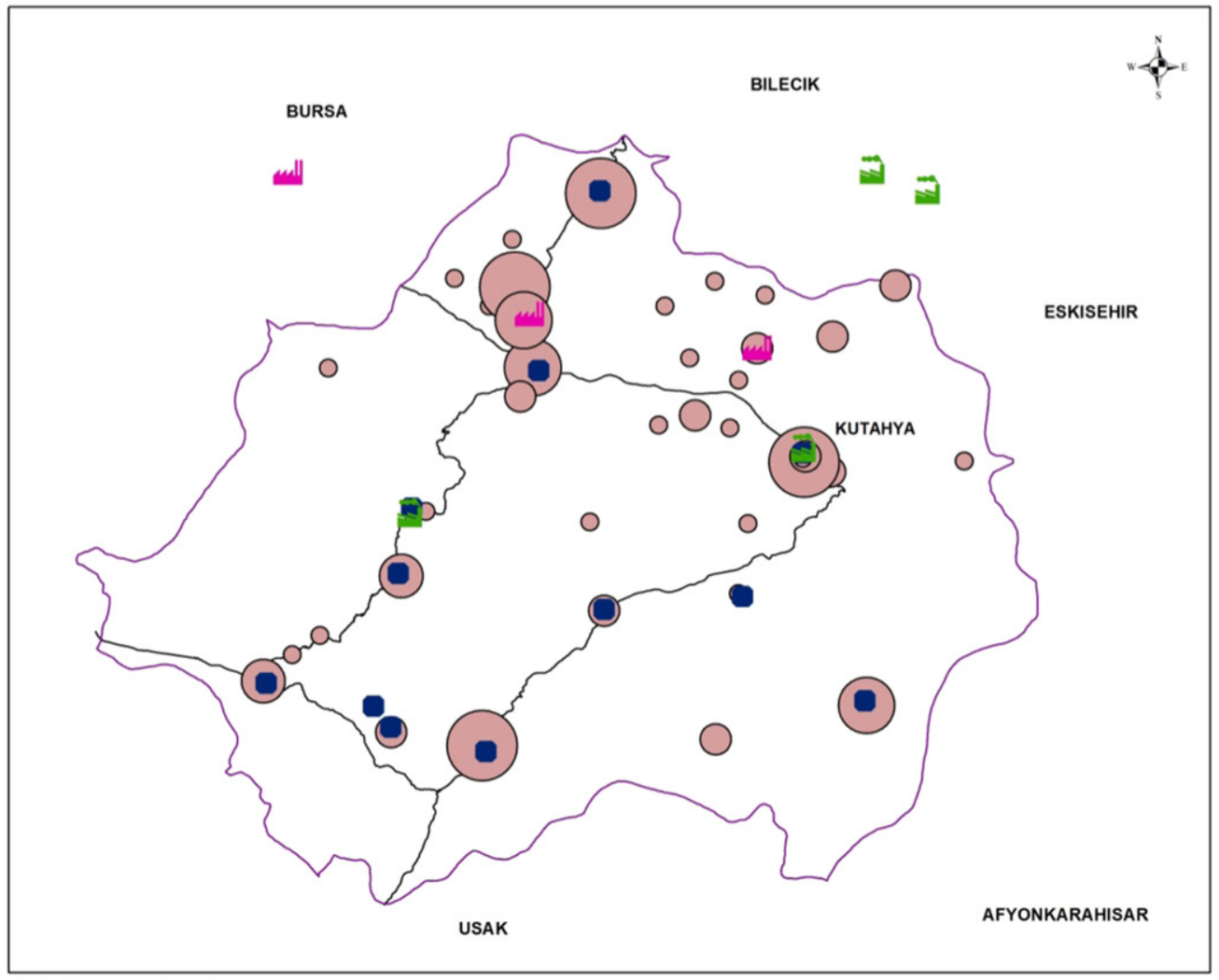

Soil (summer) $\sum 16 \mathrm{PAH}\left(\mu \mathrm{g} \mathrm{kg}^{-1}\right)$

○ $36-100$

○ $100-200$

○ $200-350$

$350-600$

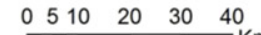

$\mathrm{Km}$

Fig. 4. Spatial distribution of soil $\Sigma_{16} \mathrm{PAH}$ concentrations $\left(\mu \mathrm{g} \mathrm{kg}{ }^{-1}\right)$ in Kutahya region. 


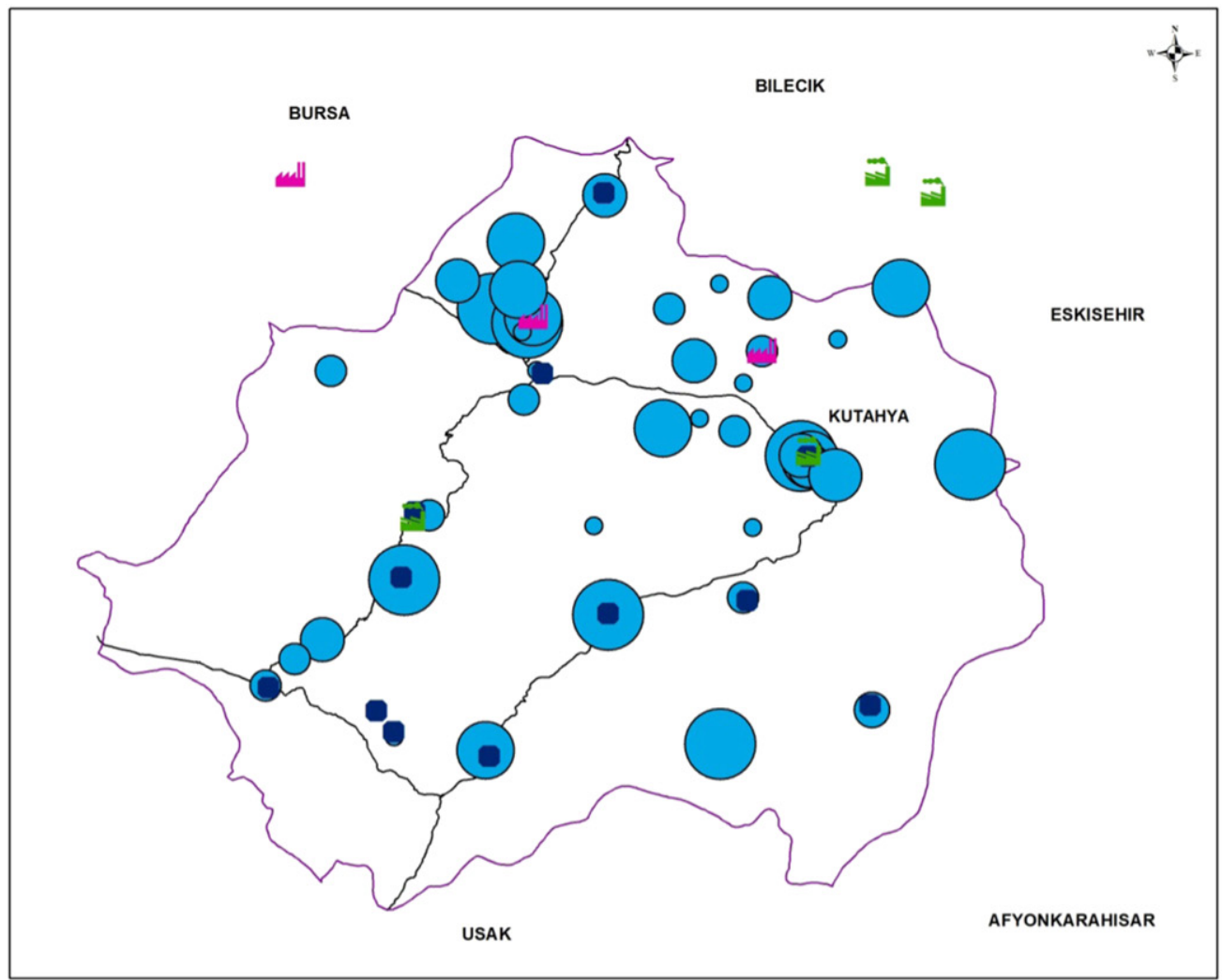

Soil (winter) ¿41 PCB $\left(\mu \mathrm{g} \mathrm{kg}^{-1}\right)$

○ $0.5-2.0$

2.0-3.0

$3.0-4.0$

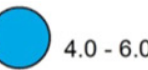

$\begin{array}{lllll}0 & 510 & 20 & 30 & 40\end{array}$

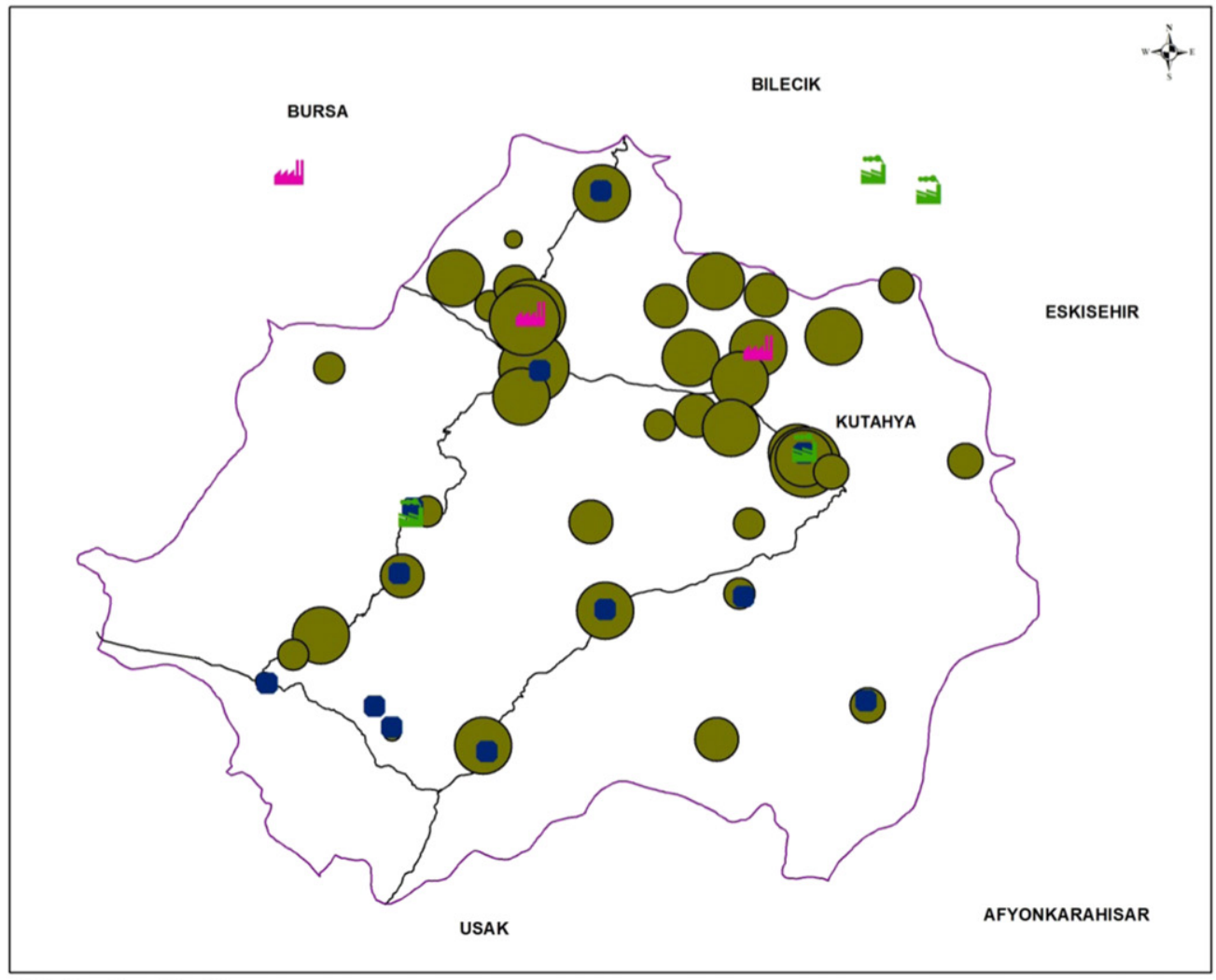

Soil (summer) ¿41 PCB $\left(\mu \mathrm{kg}^{-1}\right)$

ㅇ $1,2-1,5$

$1,5-2,0$

$2,0-3,0$

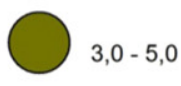

$\begin{array}{lllll}0 & 510 & 20 & 30 & 40\end{array}$

Wm

Fig. 5. Spatial distribution of soil $\Sigma_{41}$ PCB concentrations $\left(\mu \mathrm{kg}^{-1}\right)$ in Kutahya region. 


\subsection{Sources}

The spatial distribution of atmospheric and soil PAH and PCB concentrations points out that the primary sources of these pollutants in Kutahya region were power plants and residential areas. Possible $\mathrm{PAH}$ and PCB sources further explored by factor analysis.

Two factors were obtained for PAHs explaining $96.2 \%$ of the total variance. The first factor (48.9\% of the variance) was highly loaded on acenaphthylene, acenaphthene, fluorene, phenanthrene, anthracene, carbazole, fluoranthene, and pyrene, and moderately loaded on benzo[ $a$ ]anthracene, chrysene, and benzo[ $k]$ fluoranthene (Fig. 6). Carbazole is a nitrogen containing compound found in fossil fuels (i.e., coal, and crude oil) and it is mainly released from coal combustion (Odabasi et al., 2006b; Okedeyi et al., 2013; Pergal et al., 2013; Aydin et al., 2014; Wang et al., 2015). Fluoranthene, acenaphthene and pyrene have been used as coal combustion markers (Tian et al., 2009; Wang et al., 2009; Sahu et al., 2009; Lin et al., 2013). Chrysene was also reported as a marker for coke ovens and biomass/coal combustion (Wang et al., 2013; Yang et al., 2013). Anthracene, phenanthrene, fluoranthene, pyrene, and chrysene were identified as source fingerprints of wood combustion (Khalili et al., 1995). Therefore, this factor represents industrial (i.e., powerplants) and residential biomass and coal combustion emissions. The second factor ( $47.3 \%$ of the variance) was dominated by high molecular weight PAHs, i.e., benz[a]anthracene, chrysene, benzo $[b]$ fluoranthene, benzo[ $k]$ fluoranthene, benzo[ $a]$ pyrene, indeno $[1,2,3-c d]$ pyrene, dibenz $[a, h]$ anthracene, and benzo[ $g, h, i]$ perylene. Motelay-Massei et al. (2003) suggested that indeno[1,2,3-cd]pyrene and dibenz $[a, h]$ anthracene are markers for vehicular exhausts. Low volatility PAHs such as indeno[1,2,3-cd]pyrene, dibenz $[a, h]$ anthracene, and benzo[g,h,i]perylene are mainly emitted from diesel exhaust (Callen et al., 2012). Benzo[a]pyrene, indeno[1,2,3-cd]pyrene, dibenz $[a, h]$ anthracene, and benzo $[g, h, i]$ perylene were also reported as markers of gasoline exhaust emissions (Tian et al., 2013; Aydin et al., 2014). Therefore, this factor was attributed to diesel and gasoline exhaust emissions.

Three principal components were obtained for PCBs explaining $80.1 \%$ of the total variance (Fig. 6$)$. The first factor $(45.4 \%$ of the variance) had high loadings on PCB-17, PCB-18, PCB-28, PCB-31, PCB-33, PCB-49 and PCB-52 while it was moderately loaded on PCB-70, PCB95, PCB-101, PCB-99 and PCB-110. Lee et al. (2005) have reported that coal and hardwood combustion emissions are dominated by PCB-49, PCB-52, PCB-28, PCB-44, PCB-101, PCB-110, and PCB-118. Also considering that the highest $\mathrm{PCB}$ levels were observed at sites near the power plants and residential areas, this factor was attributed to coal (thermal power plants and residential heating) and wood combustion (residential heating).

The second factor (25.5\% of the variance) was primarily associated with highly chlorinated biphenyls (PCB-101, PCB-110, PCB-118, PCB138, PCB-149, PCB-151, PCB-156 PCB-180, and PCB-187) while the third factor (9.2\% of the variance) indicated high correlations for PCB44, PCB-74 and PCB-156. These compounds are the main components of technical PCB mixtures (Aroclor 1254, 1260 and Kanechlor 600) (Takasuga et al., 2005; Takasuga et al., 2006; Jin et al., 2012). Therefore, factors 2 and 3 were ascribed to evaporative emissions from previously used technical PCB mixtures. In a previous study around Seyitomer power plant in Kutahya, technical mixtures were also identified as possible sources of PCBs based on soil sampling and Chemical Mass Balance modeling (Gedik and Imamoglu, 2011).

\subsection{Air-soil exchange}

The soil fugacity fraction $\left[f_{\mathrm{S}} /\left(f_{\mathrm{S}}+f_{\mathrm{A}}\right)\right]>0.5$ implies net contaminant volatilization from soil, values $<0.5$ indicate net gas-phase deposition from air while in case of equilibrium, $f_{\mathrm{S}} /\left(f_{\mathrm{S}}+f_{\mathrm{A}}\right)$ value is $\sim 0.5$. The
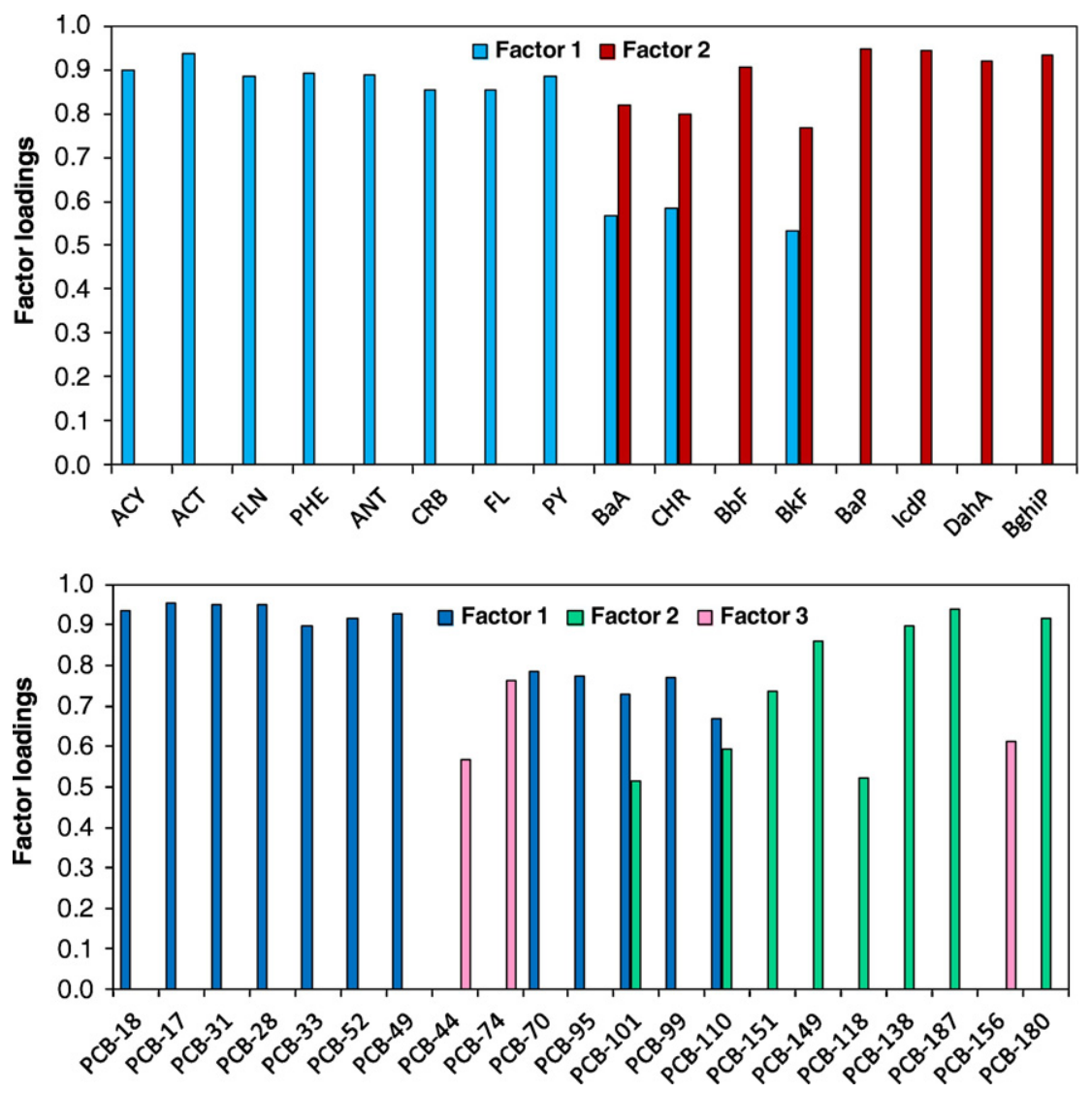

Fig. 6. Results of factor analysis for atmospheric PAHs and PCBs. 
uncertainty of the calculated fugacity fractions was estimated using a propagated error analysis. Uncertainty in $K_{S A}$ values was estimated as $<25 \%$. The uncertainties of $C_{g}$ and $C_{S}$ were taken as $15 \%$ (Bozlaker et al., 2008a; Bozlaker et al., 2008b). It should be noted that the estimation of gas-phase concentrations as described in Section 2.7 introduces additional errors that could not be assessed easily. Previously collected atmospheric concentration data in Izmir region based on active sampling (Odabasi et al., 2008; Bozlaker et al., 2008a; Bozlaker et al., 2008b; Demircioglu et al., 2011) was evaluated in terms of the partitioning model used in the present study. It was found that the modeling errors are variable for different compounds having different volatilities and for sample sets collected at different locations (i.e., suburban, urban). Model performs well (errors 1.0-20\%) for compounds with $\log K_{O A}$ values $<9.0$ while errors increase up to $~ 50 \%$ for those with $\log K_{O A}$ values $>12.0$. Variability based on site characteristics does not allow assigning certain values for modeling errors associated with $C_{\mathrm{g}}$. If a conservative modeling error of $50 \%$ is taken into account, error propagation related to estimation of $f_{\mathrm{S}} /\left(f_{\mathrm{S}}+f_{\mathrm{A}}\right)$ implies that the equilibrium is denoted by a fraction of $0.5 \pm 0.14$ (a range of $0.36-0.64$ ).

The fugacity fractions of majority of the PAHs ( $88.0 \%$ in winter, $87.4 \%$ in summer) and PCBs (76.8\% in winter, $83.8 \%$ in summer) fell outside this uncertainty range showing that for these compounds the soil and ambient air were not in equilibrium (Figs. 7 and 8). For PAHs, the number of the cases implying deposition in winter (65.6\%) was higher than volatilization (22.3\%). However, in summer there was not a dominant mechanism for PAHs (43.2\% volatilization, $44.3 \%$ deposition). For PCBs, number of cases implying volatilization in summer (59.1\%) was higher compared to those for winter (35.3\%) while deposition was higher in winter (41.5\%) compared to summer (24.7\%).

During summer, fugacity fractions for acenaphthylene, acenaphthene, fluorene, phenanthrene, anthracene and carbazole were generally $>0.64$ showing net volatilization while the fractions for fluoranthene and pyrene implied volatilization at some sites and deposition for the others. The rest of the PAHs deposited to soil (Fig. 7). During winter, acenaphthylene, acenaphthene, and fluorene were generally $>0.64$ showing net volatilization while the fractions for phenanthrene, anthracene, and carbazole showed volatilization at some sites and deposition for the others, while the remaining PAHs deposited to soil.

Fugacity fractions for low molecular weight PCBs (i.e., PCB-17, 18, $28,33,52,49,44$, and 70 ) were in general $>0.64$ during summer showing net volatilization while the fractions for a few higher chlorinated congeners (i.e., PCB-118, 138, 187, and 180) indicated deposition (Fig. 8). Most of the low molecular weight PCBs continued to volatilize in winter. On the other hand, the number of congeners indicating deposition only increased from four to seven (i.e., PCB-95, 101, 149, $118,138,187$, and 180). Results of the fugacity calculations indicated that during the year local soils generally act as a sink for medium to low volatility PAHs and PCBs and as a source for high volatility ones. Soil also becomes a source during summer for some medium to high volatility compounds.

\subsection{Population exposure and carcinogenic risks}

Monte Carlo simulation was implemented to estimate population carcinogenic risks associated with inhalation and accidental soil ingestion exposure routes. Exposure and risks were estimated for rural and urban/industrial sites separately, and for the whole dataset (rural + urban/industrial sites) in winter and summer. Fitted distributions for each input variable to the two exposure models, the estimated exposures, and their parameter values are presented in Table S7.

The estimated 95th percentile inhalation and accidental soil ingestion exposure for $\Sigma_{16}$ PAHs varied from 0.04 to $0.99 \mathrm{ng} \mathrm{kg}^{-1}$ day $^{-1}$ and from $5.71 \times 10^{-6}$ to $3.19 \times 10^{-4} \mu \mathrm{g} \mathrm{kg}^{-1}$ day $^{-1}$, respectively, among the sampling sites (Table 1 ). The ranges were 0.03 to $0.06 \mathrm{ng} \mathrm{kg}^{-1} \mathrm{day}^{-1}$ and $3.15 \times 10^{-6}$ to $5.66 \times 10^{-6} \mu \mathrm{g} \mathrm{kg}^{-1} \mathrm{day}^{-1}$ for $\Sigma_{41}$ PCBs, respectively. The median and 95th percentile inhalation
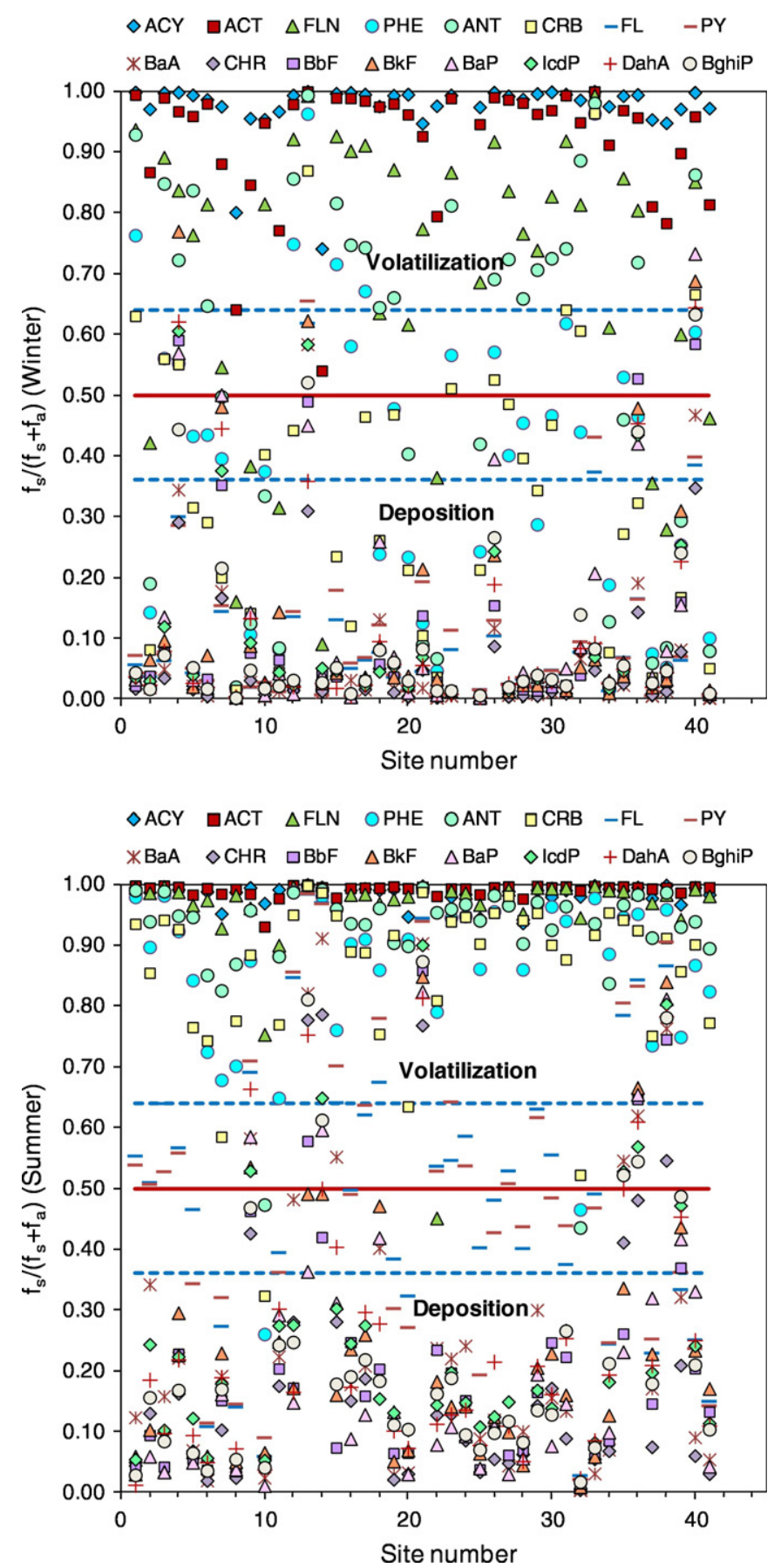

Fig. 7. Soil fugacity fractions of PAHs at different sampling sites. The solid horizontal line represents equilibrium and dashed lines indicate the uncertainty range.

and accidental soil ingestion exposure to $\Sigma_{16} \mathrm{PAHs}$ and $\Sigma_{41} \mathrm{PCBs}$ were mostly found at higher levels in colder period compared to the warmer period, and in urban/industrial sites compared to rural sites, especially for $\Sigma_{16}$ PAHs. Estimated risk frequency histograms due to inhalation and accidental soil ingestion risks of $\Sigma_{16}$ PAHs and $\Sigma_{41}$ PCBs are given in Figs. 9, 10, S1 and S2 for each period (summer and winter) and each site (rural, urban/industrial, rural + urban/industrial). The calculated cancer risks associated with the two exposure routes, inhalation and ingestion of soil for $\Sigma_{16}$ PAHs at the 95th percentile ranged from $1.62 \times 10^{-7}$ to $4.03 \times 10^{-6}$ and from $6.85 \times 10^{-8}$ to $3.52 \times 10^{-6}$, respectively. The seasonal differences showed that all the estimated risks due to both of the routes in winter are higher than those in summer. The estimated median and 95th percentile risks for $\Sigma_{16} \mathrm{PAHs}$ 

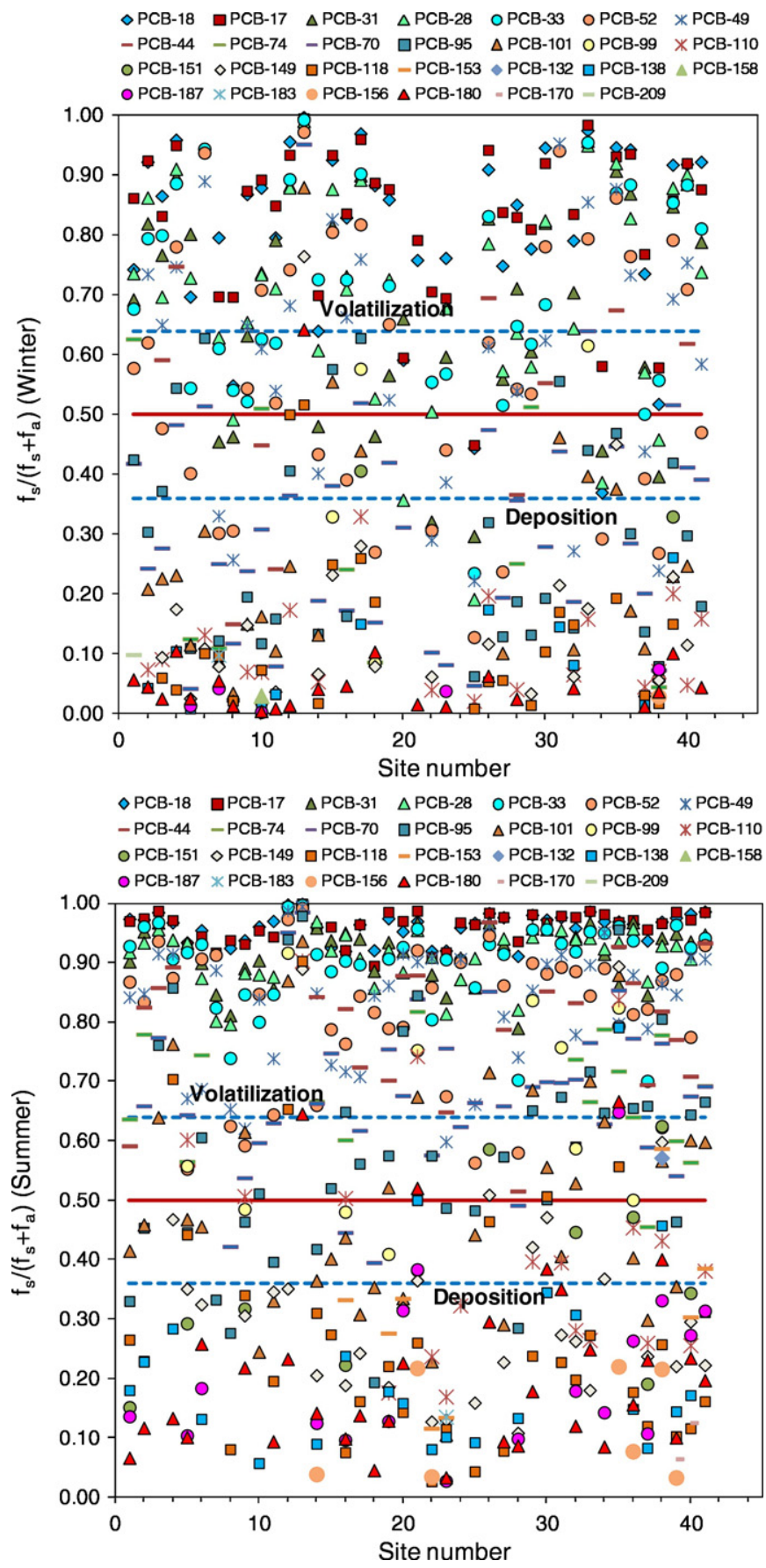

Fig. 8. Soil fugacity fractions of PCBs at different sampling sites. The solid horizontal line represents equilibrium and dashed lines indicate the uncertainty range.

were found at higher levels in urban/industrial sites compared to rural sites, except the 95th percentile inhalation risks for summer $\left(1.90 \times 10^{-7}\right.$ in rural sites and $1.62 \times 10^{-7}$ in urban/industrial sites). In five Asian countries (China, India, Japan, Korea, and Vietnam), a large-scale monitoring program was established in 2012-2013, and lung cancer risks associated with inhalation exposure to PAHs were estimated (Hong et al., 2016). The mean estimated lifetime excess inhalation cancer risks were reported as $27.8 \times 10^{-6}$ for China, $1.36 \times 10^{-6}$ for Japan, $2.45 \times 10^{-6}$ for South Korea, $21.8 \times 10^{-6}$ for Vietnam, and $9.10 \times 10^{-6}$ for India, by using a unit risk of $1.1 \times 10^{-6}$ per $\mathrm{ng} \mathrm{m}^{-3}$. All of the average lung cancer risk levels were higher than those reported in the present study. There are only three studies conducted in Turkey, estimating the carcinogenic inhalation risk due to PAHs (Gaga et al., 2012; Gungormus et al., 2014; Ugranli et al., 2016). Gungormus et al. (2014) assessed inhalation and dermal risk levels of PAH exposure during a heating period at a site in the city of Balikesir, Turkey. The inhalation risk level was recorded in the range from $1.32 \times 10^{-7}$ to $2.23 \times 10^{-4}$. Ugranli et al. (2016) analyzed the air samples collected throughout a year (May 2003-April 2004) in a suburban site in Izmir. The 95th percentile carcinogenic risks due to PAH exposure was found as $3.66 \times 10^{-6}$ in heating period and $9.08 \times 10^{-7}$ in non-heating period. The SF values used in these studies were the same as one used in the present study. The risk levels reported in this study show similarities with those reported by Ugranli et al. (2016), while they are lower than those reported by Gungormus et al. (2014), and much more lower than those by Gaga et al. (2012) who employed a BaP unit risk value of $8.7 \times 10^{-5}$ per $\mathrm{ng} \mathrm{m}^{-3}$. Yu et al. (2014) determined PAHs in 69 surface soil samples collected from Hangzhou urban districts in China. Similar to this study, the risk levels associated with exposure to soil borne PAHs were found in the range of $4.62 \times 10^{-8}$ to $2.97 \times 10^{-6}$ with a mean of $3.75 \times 10^{-7}$.

The estimated 95th percentile risk levels for $\Sigma_{41}$ PCBs ranged from $5.37 \times 10^{-8}$ to $3.47 \times 10^{-6}$ due to inhalation exposure and from $6.60 \times 10^{-9}$ to $1.16 \times 10^{-8}$ due to accidental soil ingestion exposure, respectively. The estimated inhalation risk levels in colder period are higher than those in warmer period especially at the 95th percentile, whereas they were similar for accidental soil ingestion. The inhalation risk due to $\Sigma_{41}$ PCBs were found at similar levels at rural and urban/industrial sites when medians are considered, whereas higher 95th percentile risk levels were calculated at rural sites due to much higher total dioxin-like PCB concentrations in air at three of the 18 rural sites in winter, skewing the concentration, exposure, and distributions. However, comparison of the dioxin-like PCB air concentrations between rural and urban/industrial sites indicate that the medians are not significantly different (Mann-Whitney test, $p=0.30$ ). Zhang et al. (2013) have investigated the spatial distribution of $\Sigma_{6} \mathrm{PCBs}$ in the atmosphere of urban, urban-rural transition, and rural sites in Yangtze River Delta, China. Lifetime cancer risks for PCBs associated with inhalation exposure were found as $0.127 \times 10^{-6}, 0.129 \times 10^{-6}$, and $0.070 \times 10^{-6}$ for urban, urban-rural transition, and rural dwellers, respectively. Thus, the spatial differences were in the order of urban $\approx$ urban-rural transition > rural sites. The carcinogenic risk levels due to $\mathrm{PCB}$ inhalation exposure route was estimated in only one study conducted in Turkey by Ugranli et al. (2016). The 95th percentile carcinogenic inhalation risks in heating and non-heating periods were reported as $9.64 \times 10^{-8}$ and $1.81 \times 10^{-7}$, respectively. Lu and Liu (2015) collected surface soil samples from 23 city parks ( 8 urban and 15 suburban) in Xi'An, China. The reported 95th percentile cancer risks due to inhalation and ingestion of PCBs in soil were $0.025 \times 10^{-9}$ and $0.011 \times 10^{-6}$, respectively. Similarly, the most of the estimated carcinogenic risks in the present study were lower than the acceptable risk level of $10^{-6}$. The percentage of the population exceeding the acceptable risk level ranged from $<1 \%$ to $16 \%$. As an exception, the $32 \%$ of the inhalation risk levels due to PAH exposure in winter in urban/industrial sites were found as $>10^{-6}$, with the maximum risk level of $6 \times 10^{-6}$, not reaching $10^{-5}$, the acceptable risk level preferred for some pollutants or by some countries (Kavcar et al., 2006).

Uncertainties arising from the Monte Carlo process were estimated using bootstrap analysis. The estimated uncertainties for each period in rural + urban/industrial sites are given in Table S8. Coefficient of variation (CV) for inhalation PAH and PCB exposure for both of the sampling periods were calculated as $<6 \%$ for the median and mean, while this value was in the range from $3 \%$ to $7 \%$ for ingestion exposure, indicating the uncertainties were low. As an exception, CV for PAH ingestion exposure in winter was calculated as $27 \%$ for the mean.

\section{Conclusions}

Atmospheric and concurrent soil samples were collected during two seasons in 2014 (winter and summer) at 41 sites in Kutahya, Turkey to 
Table 1

The estimated mean and 95th percentile inhalation and accidentally soil ingestion exposure and risk for $\Sigma_{16} \mathrm{PAHs}$ and $\Sigma_{41} \mathrm{PCBs}$.

\begin{tabular}{|c|c|c|c|c|c|c|c|c|}
\hline \multirow[b]{3}{*}{ Pollutant (Sampling Site/Period) } & \multicolumn{4}{|c|}{ Inhalation Route } & \multicolumn{4}{|c|}{ Accidental Soil Ingestion Route } \\
\hline & \multicolumn{2}{|c|}{ Median } & \multicolumn{2}{|c|}{ 95th percentile } & \multicolumn{2}{|l|}{ Median } & \multicolumn{2}{|c|}{ 95th percentile } \\
\hline & CDI & Risk & CDI & Risk & CDI & Risk & CDI & Risk \\
\hline$\Sigma_{16} \mathrm{PAHs}^{\mathrm{a}}$ (Rural/Winter) & 0.03 & $1.21 \times 10^{-7}$ & 0.12 & $4.66 \times 10^{-7}$ & $1.65 \times 10^{-6}$ & $1.98 \times 10^{-8}$ & $1.27 \times 10^{-5}$ & $1.53 \times 10^{-7}$ \\
\hline$\Sigma_{16} \mathrm{PAHs}$ (Rural/Summer) & 0.01 & $3.92 \times 10^{-8}$ & 0.04 & $1.90 \times 10^{-7}$ & $1.81 \times 10^{-6}$ & $2.18 \times 10^{-8}$ & $5.71 \times 10^{-6}$ & $6.85 \times 10^{-8}$ \\
\hline$\Sigma_{16} \mathrm{PAHs}$ (Urban + Industrial/Winter) & 0.16 & $6.34 \times 10^{-7}$ & 0.99 & $4.03 \times 10^{-6}$ & $1.25 \times 10^{-5}$ & $1.50 \times 10^{-7}$ & $2.29 \times 10^{-4}$ & $2.75 \times 10^{-6}$ \\
\hline$\Sigma_{16} \mathrm{PAHs}$ (Urban + Industrial/Summer) & 0.02 & $7.41 \times 10^{-8}$ & 0.05 & $1.62 \times 10^{-7}$ & $6.78 \times 10^{-6}$ & $8.14 \times 10^{-8}$ & $9.48 \times 10^{-5}$ & $1.14 \times 10^{-6}$ \\
\hline$\Sigma_{16} \mathrm{PAHs}$ (Rural + Urban + Industrial/Winter) & 0.08 & $3.21 \times 10^{-7}$ & 0.67 & $2.29 \times 10^{-6}$ & $2.71 \times 10^{-6}$ & $3.27 \times 10^{-8}$ & $3.19 \times 10^{-4}$ & $3.52 \times 10^{-6}$ \\
\hline$\Sigma_{16} \mathrm{PAHs}$ (Rural + Urban + Industrial/Summer) & 0.01 & $5.62 \times 10^{-8}$ & 0.05 & $2.09 \times 10^{-7}$ & $3.61 \times 10^{-6}$ & $4.55 \times 10^{-8}$ & $5.16 \times 10^{-5}$ & $7.58 \times 10^{-7}$ \\
\hline$\Sigma_{41} \mathrm{PCBs}^{\mathrm{b}}$ (Rural/Winter) & 0.02 & $5.84 \times 10^{-8}$ & 0.04 & $3.47 \times 10^{-6}$ & $1.08 \times 10^{-6}$ & $2.24 \times 10^{-9}$ & $4.35 \times 10^{-6}$ & $9.03 \times 10^{-9}$ \\
\hline$\Sigma_{41}$ PCBs (Rural/Summer) & 0.01 & $3.30 \times 10^{-8}$ & 0.03 & $5.69 \times 10^{-8}$ & $1.15 \times 10^{-6}$ & $2.30 \times 10^{-9}$ & $3.15 \times 10^{-6}$ & $6.60 \times 10^{-9}$ \\
\hline$\Sigma_{41}$ PCBs (Urban + Industrial/Winter) & 0.02 & $4.77 \times 10^{-8}$ & 0.06 & $1.39 \times 10^{-7}$ & $1.62 \times 10^{-6}$ & $3.23 \times 10^{-9}$ & $5.66 \times 10^{-6}$ & $1.16 \times 10^{-8}$ \\
\hline$\Sigma_{41}$ PCBs (Urban + Industrial/Summer) & 0.01 & $3.27 \times 10^{-8}$ & 0.03 & $5.37 \times 10^{-8}$ & $1.43 \times 10^{-6}$ & $3.02 \times 10^{-9}$ & $4.52 \times 10^{-6}$ & $9.80 \times 10^{-9}$ \\
\hline$\Sigma_{41} \mathrm{PCBs}$ (Rural + Urban + Industrial/Winter) & 0.02 & $4.29 \times 10^{-8}$ & 0.05 & $2.02 \times 10^{-7}$ & $1.35 \times 10^{-6}$ & $2.63 \times 10^{-9}$ & $5.09 \times 10^{-6}$ & $1.02 \times 10^{-8}$ \\
\hline$\Sigma_{41}$ PCBs (Rural + Urban + Industrial/Summer) & 0.02 & $3.36 \times 10^{-8}$ & 0.03 & $5.39 \times 10^{-8}$ & $1.31 \times 10^{-6}$ & $2.56 \times 10^{-9}$ & $3.99 \times 10^{-6}$ & $8.03 \times 10^{-9}$ \\
\hline
\end{tabular}

a Unit of CDI of $\Sigma_{16}$ PAHs: ng kg $^{-1}$ day $^{-1}$.

b Unit of CDI of $\Sigma_{41}$ PCBs: $\mu g \mathrm{~kg}^{-1} \mathrm{day}^{-1}$.

determine the spatial and seasonal variations, sources, air-soil exchange, and associated carcinogenic risks of polycyclic aromatic hydrocarbons (PAHs) and polychlorinated biphenyls (PCBs).

The highest air and soil concentrations were observed near the power plants and residential sites and the wintertime concentrations were generally higher than those measured in summer. Low molecular weight compounds i.e., phenanthrene, fluorene, fluoranthene, and pyrene dominated the $\Sigma_{16} \mathrm{PAH}$ concentration measured in ambient air while soil concentrations were dominated by medium to high molecular weight compounds (phenanthrene, fluoranthene, pyrene, chrysene, benzo[ $b]$ fluoranthene, benzo[ $k]$ fluoranthene). Low molecular weight congeners (PCB-17, 18, 28, 31, 33, 44, 49, and 52) dominated the atmospheric $\Sigma_{41} \mathrm{PCB}$ concentrations while there were no largely dominating congeners in soil.

The spatial distribution of measured ambient concentrations and results of the factor analysis showed that the major contributing $\mathrm{PAH}$ sources in the region were the coal combustion for power generation and residential heating (48.9\%) and diesel and gasoline exhaust emissions (47.3\%) while the major PCB sources were coal (thermal power plants and residential heating) and wood combustion (residential heating) (45.4\%) and evaporative emissions from previously used technical PCB mixtures (34.7\%).
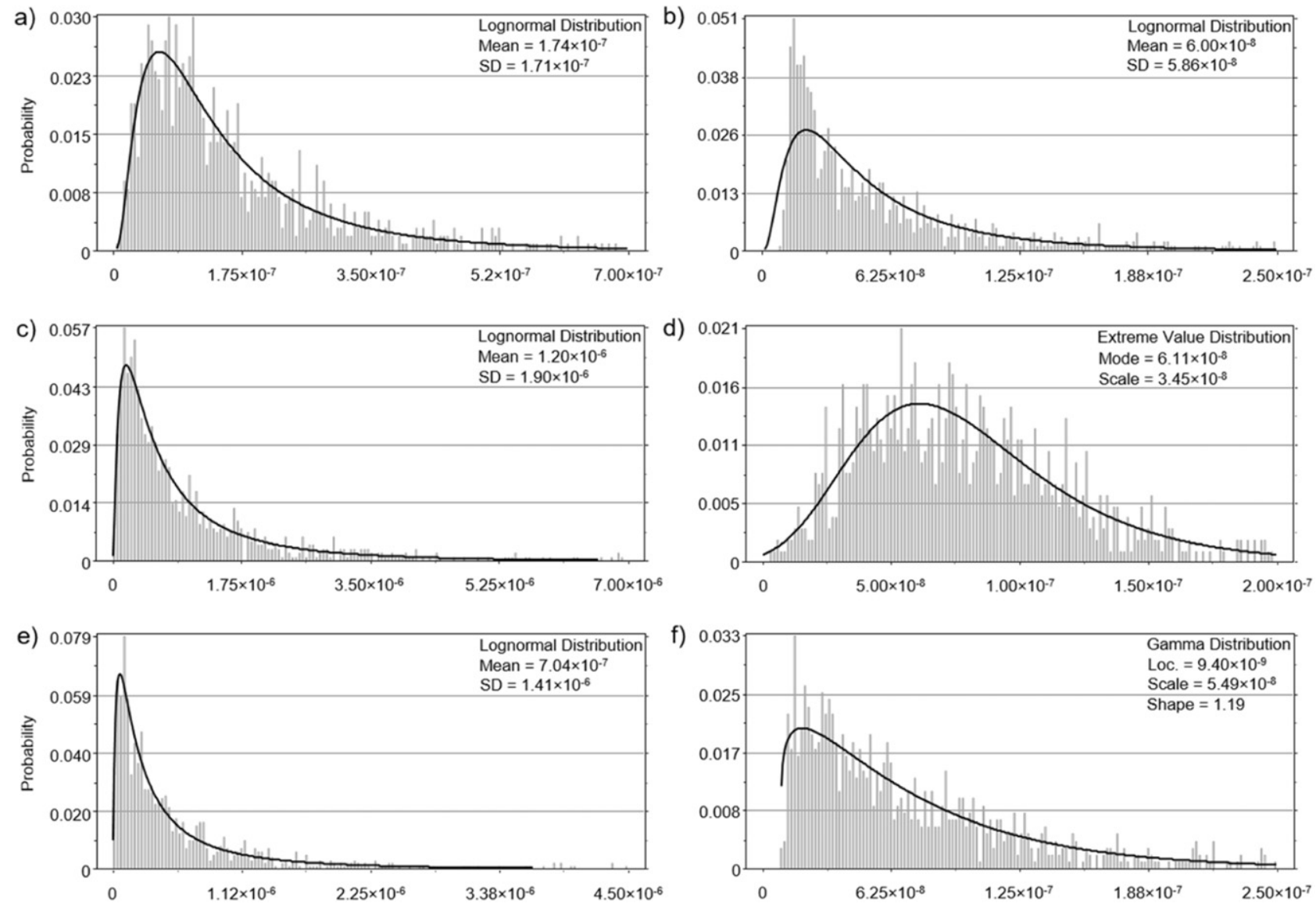

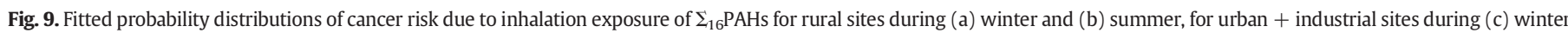
and (d) summer, and for rural + urban/industrial sites during (e) winter and (f) summer. 

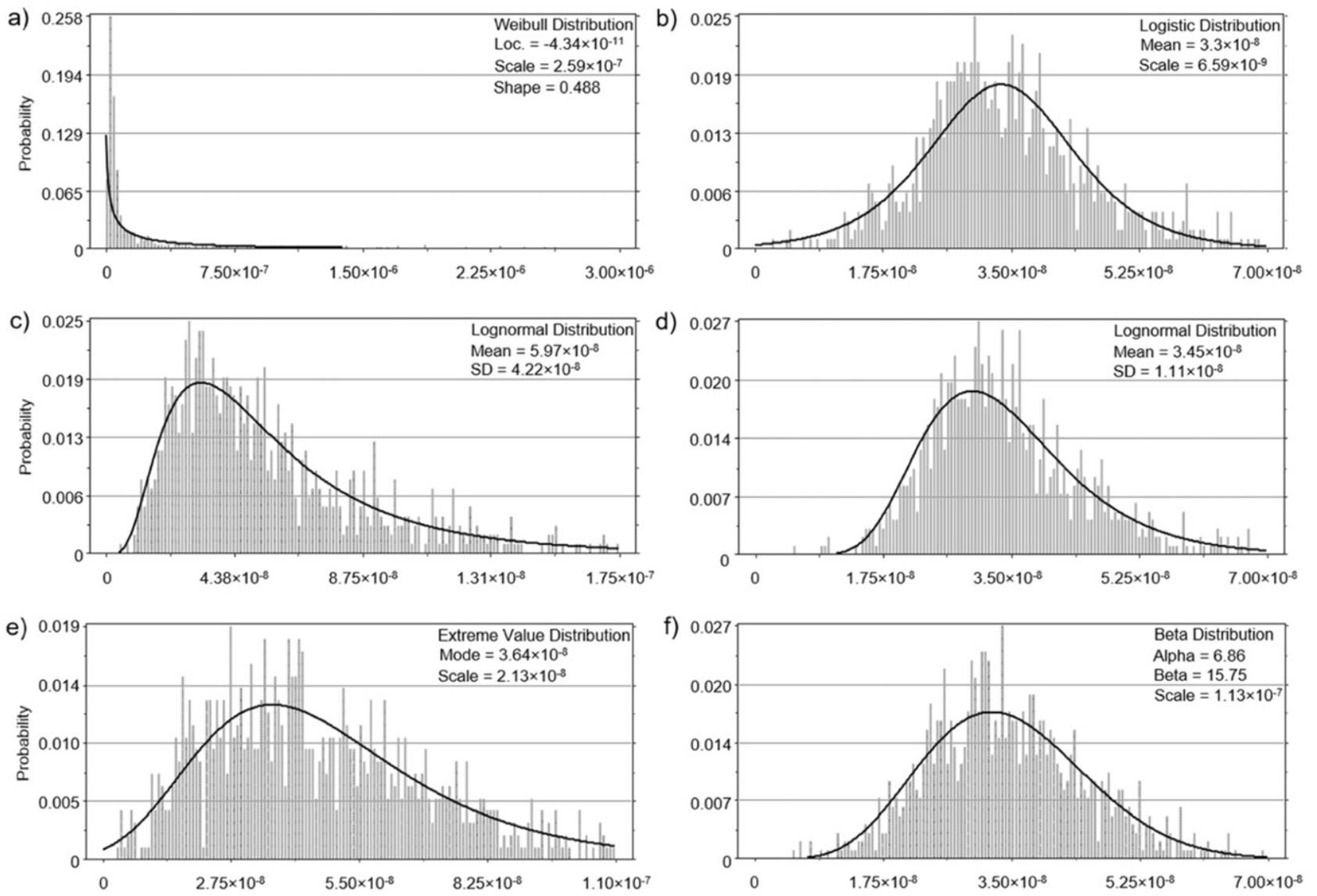

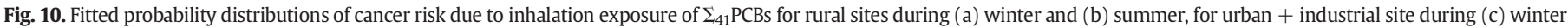
and (d) summer, and for rural + urban/industrial sites during (e) winter and (f) summer.

Results of fugacity fraction calculations indicated that the soil and atmosphere were not in equilibrium for most of the PAHs ( $83.4 \%$ in winter, $77.9 \%$ in summer) and PCBs (66.8\% in winter, $72.0 \%$ in summer). For PAHs, deposition to the soil was the dominant mechanism in winter while in summer they mostly volatilized. However, for PCBs number of cases implying volatilization was higher compared to deposition in both seasons.

Cancer risks associated with inhalation and accidental soil ingestion of soil were also estimated. Generally, the estimated carcinogenic risks were below the acceptable risk level of $10^{-6}$. The percentage of the population exceeding the acceptable risk level ranged from $<1 \%$ to $16 \%$, except, $32 \%$ of the inhalation risk levels due to $\mathrm{PAH}$ exposure in winter in urban/industrial sites were $>10^{-6}$.

\section{Acknowledgment}

This study was supported by The Scientific and Technological Research Council of Turkey (project no: TUB/112Y305) and by Anadolu University research fund for scientific projects (project no: 1306F272). We would like to thank Gizem Tuna Tuygun and Hasan Altiok (Dokuz Eylul University) for their support during the study.

\section{Appendix A. Supplementary data}

Supplementary data to this article can be found online at http://dx. doi.org/10.1016/j.scitotenv.2016.12.040.

\section{References}

ATSDR, 2005. Public Health Assessment Guidance Manual Appendix G: Calculating Exposure Doses (Agency for Toxic Substances and Disease Registry).
Aydin, Y.M., Kara, M., Dumanoglu, Y., Odabasi, M., Elbir, T., 2014. Source apportionment of polycyclic aromatic hydrocarbons (PAHs) and polychlorinated biphenyls (PCBs) in ambient air of an industrial region in Turkey. Atmos. Environ. 97, 271-285.

Ayris, S., Harrad, S., 1999. The fate and persistence of polychlorinated biphenyls in soil. J. Environ. Monit. 1, 395-401.

Badawy, M.I., El-Wahaab, R.A., Moawad, A., Ali, M.E.M., 2010. Assessment of the performance of aerated oxidation ponds in the removal of persistent organic pollutants (POPs): a case study. Desalination 251, 29-33.

Bidleman, T.F., Leone, A.D., 2004. Soil-air exchange of organochlorine pesticides in the Southern United States. Environ. Pollut. 128, 49-57.

Biterna, M., Voutsa, D., 2005. Polychlorinated biphenyls in ambient air of NW Greece and in particulate emissions. Environ. Int. 31, 671-677.

Bozlaker, A., Muezzinoglu, A., Odabasi, M., 2008a. Atmospheric concentrations, dry deposition and airesoil exchange of polycyclic aromatic hydrocarbons (PAHs) in an industrial region in Turkey. J. Hazard. Mater. 153, 1093-1102.

Bozlaker, A., Odabasi, M., Muezzinoglu, A., 2008b. Dry deposition and soil-air gas exchange of polychlorinated biphenyls (PCBs) in an industrial area. Environ. Pollut. 156, 784-793.

Breivik, K., Sweetman, A., Pacyna, J.M., Jones, K.C., 2002. Towards a global historical emission inventory for selected PCB congeners: a mass balance approach 1. Global production and consumption. Sci. Total Environ. 290, 181-198.

CalEPA, 2015. Air Toxics Hot Spots Program Guidance Manual for Preparation of Health Risk Assessments. Office of Environmental Health Hazard Assessment, Oakland, CA.

Callen, M.S., Lopez, J.M., Mastral, A.M., 2012. Apportionment of the airborne PM10 in Spain. Episodes of potential negative impact for human health. J. Environ. Monit. 14, 1211-1220.

Cetin, B., Yatkin, S., Bayram, A., Odabasi, M., 2007. Ambient concentrations and source apportionment of PCBs and trace elements around an industrial area in Izmir, Turkey. Chemosphere 69, 1267-1277.

Chen, J., Xue, X., Schramm, K.W., Quan, X., Yang, F., Kettrup, A., 2002. Quantitative structure-property relationships for octanol-air partition coefficients of polychlorinated biphenyls. Chemosphere 48, 535-544.

Demircioglu, E., Sofuoglu, A., Odabasi, M., 2011. Atmospheric concentrations and phase partitioning of polycyclic aromatic hydrocarbons in Izmir, Turkey. Clean: Soil, Air, Water 39, 319-327.

Dyke, P.H., Foan, C., Fiedler, H., 2003. PCB and PAH releases from power stations and waste incineration processes in the UK. Chemosphere 50, 469-480.

Gaga, E.O., 2016. Unpublished Results. Anadolu University, Eskisehir, Turkey.

Gaga, E.O., Ari, A., Dogeroglu, T., Cakirca, E.E., Machin, N.E., 2012. Atmospheric polycyclic aromatic hydrocarbons in an industrialized city, Kocaeli, Turkey: study of seasonal 
variations, influence of meteorological parameters and health risk estimation. J. Environ. Monit. 14, 2219-2229.

Gedik, K., Imamoglu, I., 2011. A preliminary investigation of the environmental impact of a thermal power plant in relation to PCB contamination. Environ. Sci. Pollut. Res. 18, 968-977.

Gueguen, F., Stille, P., Millet, M., 2011. Air quality assessment by tree bark biomonitoring in urban, industrial and rural environments of the Rhine Valley: PCDD/Fs, PCBs and trace metal evidence. Chemosphere 85, 195-202.

Gungormus, E., Tuncel, S., Tecer, L.H., Sofuoglu, S.C., 2014. Inhalation and dermal exposure to atmospheric polycyclic aromatic hydrocarbons and associated carcinogenic risks in a relatively small city. Ecotoxicol. Environ. Saf. 108, 106-113.

Harner, T., Bidleman, T.F., 1996. Measurements of octanol-air partition coefficients for polychlorinated biphenyls. J. Chem. Eng. Data 41, 895-899.

Harner, T., Bidleman, T.F., 1998. Octanol-air partition coefficient for describing particle/gas partitioning of aromatic compounds in urban air. Environ. Sci. Technol. 32, 1494-1502.

Harner, T., Green, N.J.L., Jones, K.C., 2000. Measurements of octanol-air partition coefficients for PCDD/Fs: a tool in assessing air-soil equilibrium status. Environ. Sci. Technol. 34, 3109-3114.

Harner, T., Su, K., Genualdi, S., Karpowicz, J., Ahrens, L., Mihele, C., Schuster, J., Charland, J.P., Narayan, J., 2013. Calibration and application of PUF disk passive air samplers for tracking polycyclic aromatic compounds (PACs). Atmos. Environ. 75, 123-128.

Harner, T., Mitrovic, M., Ahrens, L., Schuster, J., 2014. Characterization of PUF disk passive air samplers for new priority chemicals: a review. Organohalogen Compd. 76, 11-29.

Health Canada, 2004. Trichloroethylene in Drinking Water, Document for Public Comment (Prepared by the Federal-Provincial-Territorial Committee on Drinking Water).

Hippelein, M., McLachlan, M.S., 1998. Soil/air partitioning of semivolatile organic compounds. 1. Method development and influence of physical-chemical properties. Environ. Sci. Technol. 32, 310-316.

Hong, W.J., Jia, H., Ma, W.L., Sinha, R.K., Moon, H.B., Nakata, H., Minh, N.H., Chi, K.H., Li, W.L., Kannan, K., Sverko, E., Li, Y.F., 2016. Distribution, fate, inhalation exposure and lung cancer risk of atmospheric polycyclic aromatic hydrocarbons in some Asian countries. Environ. Sci. Technol. 50, 7163-7174.

Jin, R.H., Park, S.U., Park, J.E., Kim, J.G., 2012. Polychlorinated biphenyl congeners in river sediments: distribution and source identification using multivariate factor analysis. Arch. Environ. Contam. Toxicol. 62, 411-423.

Kavcar, P., Odabasi, M., Kitis, M., Inal, F., Sofuoglu, S.C., 2006. Occurrence, oral exposure and risk assessment of volatile organic compounds in drinking water for Izmir. Water Res. 40 (17), 3219-3230.

Kaya, E., Dumanoglu, Y., Kara, M., Altiok, H., Bayram, A., Elbir, T., Odabasi, M., 2012. Spatial and temporal variation and air-soil exchange of atmospheric PAHs and PCBs in an industrial region. Atmos. Pollut. Res. 3, 435-449.

Khalili, N.R., Scheff, P.A., Holsen, T.M., 1995. PAH source fingerprints for coke ovens, diesel and gasoline-engines, highway tunnels, and wood combustion emissions. Atmos. Environ. 29, 533-542.

Larsen, J.C., Larsen, P.B., 1998. Chemical carcinogens. In: Hester, R.E., Harrison, R.M. (Eds.), Air Pollution and Health. The Royal Society of Chemistry, pp. 33-56.

Lee, R.G.M., Coleman, P., Jones, J.L., Jones, K.C., Lohmann, R., 2005. Emission factors and importance of PCDD/Fs, PCBs, PCNs, PAHs and PM10 from the domestic burning of coal and wood in the UK. Environ. Sci. Technol. 39, 1436-1447.

Lin, T., Qin, Y.W., Zheng, B.H., Li, Y.Y., Chen, Y., Guo, Z.G., 2013. Source apportionment of polycyclic aromatic hydrocarbons in the Dahuofang Reservoir, Northeast China. Environ. Monit. Assess. 185, 945-953.

Lu, H., Liu, W., 2015. Characterization and risk assessment of polychlorinated biphenyls in City Park soils of Xi'An, China. Bull. Environ. Contam. Toxicol. 94, 393-398.

Markovic, M.Z., Prokop, S., Staebler, R.M., Liggio, J., Harner, T., 2015. Evaluation of the particle infiltration efficiency of three passive samplers and the PS-1 active air sampler. Atmos. Environ. 112, 289-293.

Matz, C.J., Stieb, D.M., Brion, O., 2015. Urban-rural differences in daily time-activity patterns, occupational activity and housing characteristics. Environ. Health 14:88. http://dx.doi.org/10.1186/s12940-015-0075-y.

Meijer, S.N., Harner, T., Helm, P.A., Halsall, C.J., Johnston, A.E., Jones, K.C., 2001. Polychlorinated naphthalenes in UK soils: time trends, markers of source, and equilibrium status. Environ. Sci. Technol. 35, 4205-4213.

Meijer, S.N., Ockenden, W.A., Sweetman, A., Breivik, K., Grimalt, J.O., Jones, K.C., 2003. Global distribution and budget of PCBs and HCB in background surface soils: implications for sources and environmental processes. Environ. Sci. Technol. 37, 667-672.

Motelay-Massei, A., Ollivon, D., Garban, B., Chevreuil, M., 2003. Polycyclic aromatic hydrocarbons in bulk deposition at a suburban site: assessment by principal component analysis of the influence of meteorological parameters. Atmos. Environ. 37, 3135-3146.

Nisbet, I.C., LaGoy, P.K., 1992. Toxic equivalency factors (TEFs) for polycyclic aromatic hydrocarbons (PAHs). Regul. Toxicol. Pharmacol. 16, 290-300.

Odabasi, M., Cetin, E., Sofuoglu, A., 2006a. Determination of octanol-air partition coefficients and supercooled liquid vapor pressures of PAHs as a function of temperature: application to gas-particle partitioning in an urban atmosphere. Atmos. Environ. 40, 6615-6625.

Odabasi, M., Cetin, B., Sofuoglu, A., 2006b. Henry's law constant, octanol air partition coefficient and supercooled liquid vapor pressure of carbazole as a function of temperature: application to gas/particle partitioning in the atmosphere. Chemosphere 62, 1087-1096.

Odabasi, M., Cetin, B., Demircioglu, E., Sofuoglu, A., 2008. Air-water exchange of polychlorinated biphenyls (PCBs) and organochlorine pesticides (OCPs) at a coastal site in Izmir Bay, Turkey. Mar. Chem. 109, 115-129.

Odabasi, M., Bayram, A., Elbir, T., Seyfioglu, R., Dumanoglu, Y., Bozlaker, A., Demircioglu, H., Altiok, H., Yatkin, S., Cetin, B., 2009. Electric arc furnaces for steel-making: hot spots for persistent organic pollutants. Environ. Sci. Technol. 43, 5205-5211.
Odabasi, M., Bayram, A., Elbir, T., Seyfioglu, R., Dumanoglu, Y., Ornektekin, S., 2010. Investigation of soil concentrations of persistent organic pollutants, trace elements, and anions due to iron-steel plant emissions in an industrial region in Turkey. Water Air Soil Pollut. 213, 375-388.

Odabasi, M., Falay, E.O., Tuna, G., Altiok, H., Kara, M., Dumanoglu, Y., Bayram, A., Tolunay D., Elbir, T., 2015. Biomonitoring the spatial and historical variations of persistent organic pollutants (POPs) in an industrial region. Environ. Sci. Technol. 49, 2105-2114

Odabasi, M., Dumanoglu, Y., Ozgunerge Falay, E., Tuna, G., Altiok, H., Kara, M., Bayram, A. Tolunay, D., Elbir, T., 2016. Investigation of spatial distributions and sources of persistent organic pollutants (POPs) in a heavily polluted industrial region using tree components. Chemosphere $160,114-125$.

Okedeyi, O.O., Nindi, M.M., Dube, S., Awofolu, O.R., 2013. Distribution and potential sources of polycyclic aromatic hydrocarbons in soils around coal-fired power plants in South Africa. Environ. Monit. Assess. 185, 2073-2082.

Pergal, M.M., Tesic, Z.L., Popovic, A.R., 2013. Polycyclic aromatic hydrocarbons: temperature driven formation and behavior during coal combustion in a coal-fired power plant. Energy Fuel 27, 6273-6278.

Ravindra, K., Sokhi, R., Van Grieken, R., 2008. Atmospheric polycyclic aromatic hydrocarbons: source attribution, emission factors and regulation. Atmos. Environ. 42 2895-2921.

Sahu, S.K., Bhangare, R.C., Ajmal, P.Y., Sharma, S., Pandit, G.G., Puranik, V.D., 2009. Characterization and quantification of persistent organic pollutants in fly ash from coal fueled thermal power stations in India. Microchem. J. 92, 92-96.

Shoeib, M., Harner, T., 2002. Characterization and comparison of three passive air samplers for persistent organic pollutants. Environ. Sci. Technol. 36, 4142-4151.

Takasuga, T., Kumar, K.S., Noma, Y., Sakai, S., 2005. Chemical characterization of polychlorinated biphenyls, -dibenzo-p-dioxins, and-dibenzofurans in technical kanechlor PCB formulations in Japan. Arch. Environ. Contam. Toxicol. 49, 385-395.

Takasuga, T., Senthilkumar, K., Matsumura, T., Shiozaki, K., Sakai, S.I., 2006. Isotope dilution analysis of polychlorinated biphenyls (PCBs) in transformer oil and global commercial PCB formulations by high resolution gas chromatography-high resolution mass spectrometry. Chemosphere 62, 469-484.

Tian, F.L., Chen, J.W., Qiao, X.L., Wang, Z., Yang, P., Wang, D.G., Ge, L.K., 2009. Sources and seasonal variation of atmospheric polycyclic aromatic hydrocarbons in Dalian, China: factor analysis with non-negative constraints combined with local source fingerprints. Atmos. Environ. 43, 2747-2753.

Tian, Y.Z., Li, W.H., Shi, G.L., Feng, Y.C., Wang, Y.Q., 2013. Relationships between PAHs and PCBs, and quantitative source apportionment of PAHs toxicity in sediments from Fenhe reservoir and watershed. J. Hazard. Mater. 248, 89-96.

Ugranli, T., Gungormus, E., Kavcar, P., Demircioglu, E., Odabasi, M., Sofuoglu, S.C., Lammel, G., Sofuoglu, A., 2016. POPs in a major conurbation in Turkey: ambient air concentrations, seasonal variation, inhalation and dermal exposure, and associated carcinogenic risks. Environ. Sci. Pollut. Res. 23, 22500-22512.

Ukiwe, L.N., Egereonu, U.U., Njoku, P.C., Nwoko, C.I.A., Allinor, J.I., 2013. Polycyclic aromatic hydrocarbons degradation techniques: a review. Int. J. Chem. 5, 43-55.

UNEP (United Nations Environmental Programme), 1999. Guidelines for the Identification of PCBs and Materials Containing PCBs. Prepared by UNEP Chemicals, First issue. http://www.chem.unep.ch/pops/pdf/PCBident/pcbid1.pdf (accessed in April 2013).

USEPA, 1996. PCBs: Cancer Dose-response Assessment and Application to Environmental Mixtures. US Environmental Protection Agency, Washington, DC.

USEPA, 2002a. OSWER Draft Guidance for Evaluating the Vapor Intrusion to Indoor Air Pathway from Groundwater and Soils (Subsurface Vapor Intrusion Guidance). US Environmental Protection Agency, Washington, DC.

USEPA, 2002b. Rocky Mountain Flats Human Health Risk Assessment, Task 3 Report \& Appendices, Figure A-5. p. 139.

USEPA, 2005. Guidelines for Carcinogen Risk Assessment, Risk Assessment Forum. US Environmental Protection Agency, Washington, DC.

USEPA, 2007. Slope Factors (SF) for Carcinogens. US Environmental Protection Agency, Washington, DC.

USEPA, 2010. Recommended Toxicity Equivalence Factors (TEFs) for Human Health Risk Assessments of 2,3,7,8-Tetrachlorodibenzo-p-dioxin and Dioxin-like Compounds. US Environmental Protection Agency, Washington, DC.

USEPA, 2011. Exposure Factors Handbook, EPA/600/R-090/052F. Office of Research and Development National Center for Environmental Assessment. US Environmental Protection Agency, Washington, DC.

Vallack, H.W., Bakker, D.J., Brandt, I., Brostrom-Lunden, E., Brouwer, A., Bull, K.R., Gough, C., Guardans, R., Holoubek, I., Jansson, B., Koch, R., Kuylenstierna, J., Lecloux, A. Mackay, D., McCutcheon, P., Mocarelli, P., Taalman, R.D.F., 1998. Controlling persistent organic pollutants e what next? Environ. Toxicol. Pharmacol. 6, 143-175.

Vardar, N., Esen, F., Tasdemir, Y., 2008. Seasonal concentrations and partitioning of PAHs in a suburban site of Bursa, Turkey. Environ. Pollut. 155, 298-307.

Wang, R.W., Liu, G.J., Chou, C.L., Liu, J.J., Zhang, J.M., 2009. Environmental assessment of PAHs in soils around the Anhui Coal District, China. Arch. Environ. Contam. Toxicol. $59,62-70$

Wang, X.T., Miao, Y., Zhang, Y., Li, Y.C., Wu, M.H., Yu, G., 2013. Polycyclic aromatic hydrocarbons (PAHs) in urban soils of the megacity Shanghai: occurrence, source apportionment and potential human health risk. Sci. Total Environ. 447, 80-89.

Wang, R., Liu, G., Zhang, J., 2015. Variations of emission characterization of PAHs emitted from different utility boilers of coal-fired power plants and risk assessment related to atmospheric PAHs. Sci. Total Environ. 538, 180-190.

Weber, R., Lino, F., Imagawa, T., Takeuchi, M., Sakurai, T., Sadakata, M., 2001. Formation of PCDF, PCDD, PCB and PCN in de novo synthesis from PAH: mechanistic aspects and correlation to fluidized bed incinerators. Chemosphere 44, 1429-1438.

Yang, B., Zhou, L.L., Xue, N.D., Li, F.S., Li, Y.W., Vogt, R.D., Cong, X., Yan, Y.Z., Liu, B., 2013 Source apportionment of polycyclic aromatic hydrocarbons in soils of Huanghuai plain, China: comparison of three receptor models. Sci. Total Environ. 443, 31-39. 
Yu, G., Zhang, Z., Yang, G., Zheng, W., Xu, L., Cai, Z., 2014. Polycyclic aromatic hydrocarbons in urban soils of Hangzhou: status, distribution, sources, and potential risk. Environ. Monit. Assess. 186, 2775-2784.

Zhang, X.M., Schramm, K.W., Henkelmann, B., Klimm, C., Kaune, A., Kettrup, A., Lu, P.C.

1999. A method to estimate the octanol-air partition coefficient of semivolatile organic compounds. Anal. Chem. 71, 3834-3838.
Zhang, L., Dong, L., Yang, W., Zhou, L., Shi, S., Zhang, X., Niu, S., Li, L., Wu, Z., Huang, Y., 2013. Passive air sampling of organochlorine pesticides and polychlorinated biphenyls in the Yangtze River Delta, China: concentrations, distributions, and cancer risk assessment. Environ. Pollut. 181, 159-166. 